REWORK OF MULTILAYER PRINTED

WIRING BOARD ASSEMBLIES

Published August 1976

Project Leader:

D. W. Clements

Department 845

Project Team:

R. K. Johnson

R. S. Morris

J. L. Wilson

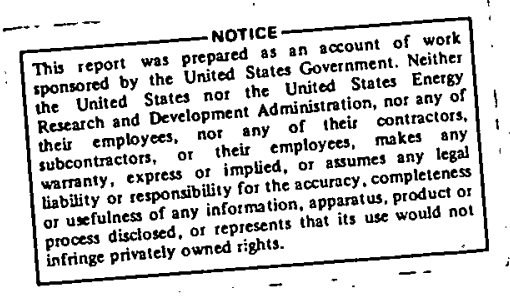

PDO 6984836

Milestone Report

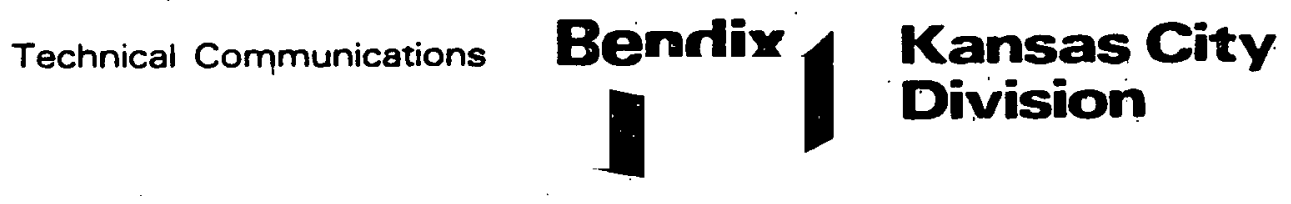




\section{DISCLAIMER}

This report was prepared as an account of work sponsored by an agency of the United States Government. Neither the United States Government nor any agency Thereof, nor any of their employees, makes any warranty, express or implied, or assumes any legal liability or responsibility for the accuracy, completeness, or usefulness of any information, apparatus, product, or process disclosed, or represents that its use would not infringe privately owned rights. Reference herein to any specific commercial product, process, or service by trade name, trademark, manufacturer, or otherwise does not necessarily constitute or imply its endorsement, recommendation, or favoring by the United States Government or any agency thereof. The views and opinions of authors expressed herein do not necessarily state or reflect those of the United States Government or any agency thereof. 


\section{DISCLAIMER}

Portions of this document may be illegible in electronic image products. Images are produced from the best available original document. 


\title{
REWORK OF MULTILAYER PRINTED WIRING BOARD ASSEMBLIES
}

\section{BDX-613-1315, UNCLASSIFIED Milestone Report, Published August 1976}

\author{
Prepared by D. W. Clements, D/845, under PDO 6984836
}

The effectiveness of several commonly used techniques for reworking multilayer printed wiring board (MLPWB) assemblies are investigated. Reworked assemblies are evaluated to determinel what rework situations are potential problems and what rework techniques minimize the probability of damaging the MLPWBs. Special attention is given to evaluating the reliability of MLPWB internal connections after rework.

This report was prepared as an account of work sponsored by the United States Government. Neither the United States nor the United States Energy Research and Development Administration, nor any of their employees, nor any of their contractors; subcontractors; or their employees, makes any warranty, express or implied, or assumes any legal liability or responsibility for the accuracy, completeness or usefulness of any information, apparatus, product or process disclosed, or represents that its use would not infringe privately owned rights.
THE BENDIX CORPORATION

KANSAS CITY DIVISION

P.O. BOX 1159

KANSAS CITY, MISSOURI 64141

A prime contractor for the United States Energy Research and Development Administration Contract Number E(29-1)-613 USERDA 
CONTENTS

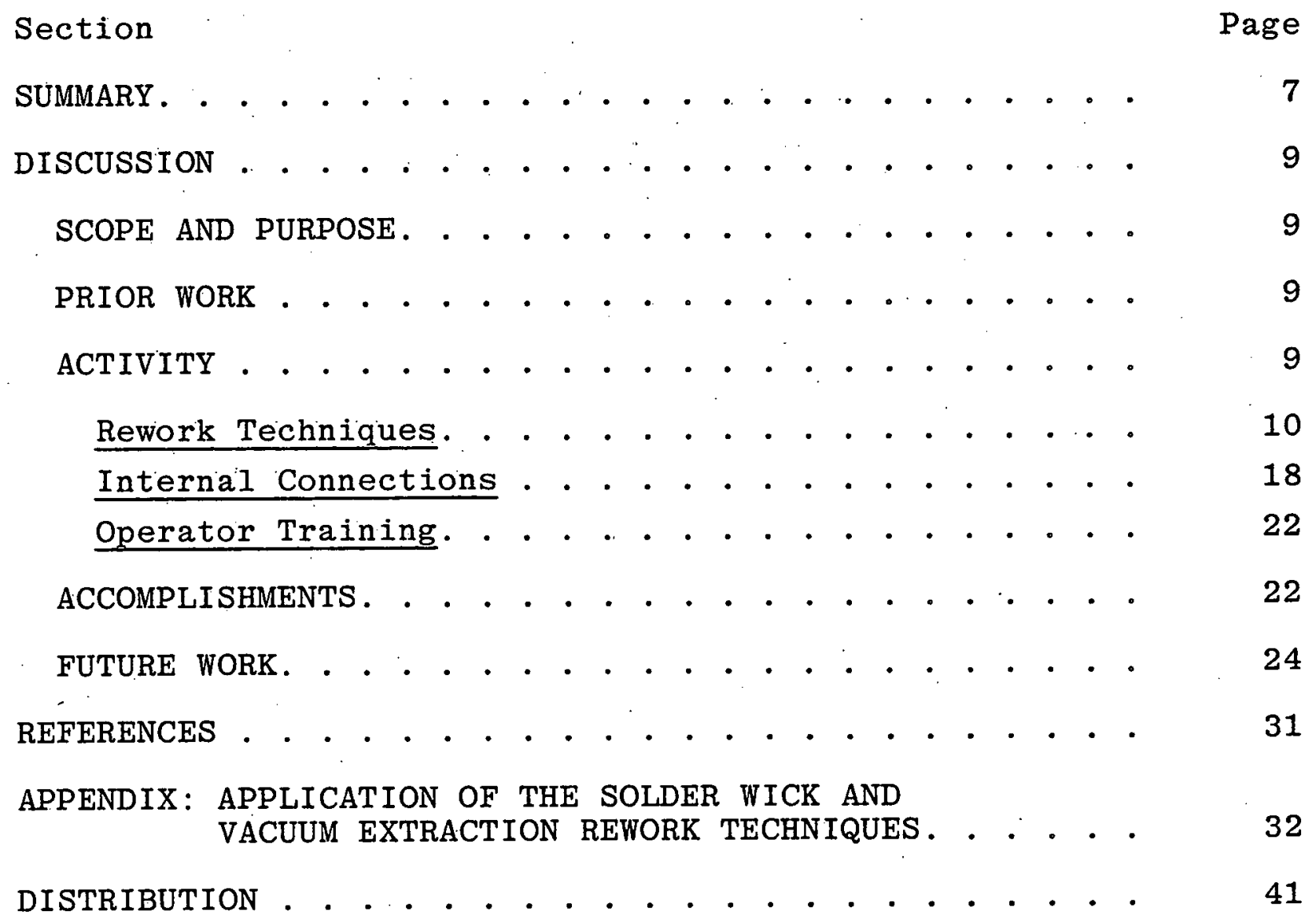




\section{ILLUSTRATIONS}

Figure

Page

1

Overal1. View of a Group 1 Assembly

(Polaroid).

Close-Up View of a Group 1 Assembly

Showing Connection of PWAs to

Multilayer Mother Board (Polaroid). . . .

Blister Caused by Wave Heat and Pull

Technique (Polaroid). . . . . . . . . .

"Worst Case" Comparison of Vacuum

Extraction and Solder Wick Techniques (Polaroid).

Overall View of Group 2. Assembly

(Polaroid).

Header Terminal Area Before Rework Attempt (Polaroid).

Header Terminal Area After Vacuum

Extraction; Sweat Joints Remain

Between PTHs and Pins (Polaroid). . . . : .

Header Terminal Area After Sweat

Joints Removed by Forced Exhaust;

Header Can Now be Lifted Off MLPWB

(Polaroid) . . . . . . . . . . . . . .

9 Probability of Damage Versus Number of Component Leads . . . . . . . . . . .

Probability of Damage Versus Tightness of Fit.. . . . . . . . . . . . . .

Probability of Damage Versus Board Thickness. . . . . . . . . . . . . . . 25 
Sixteen Lead DIP Pattern After Solder Removed by Vacuum Extraction;

IC Can Now Be Lifted Off MLPWB . . . . . .

PTH Damaged During Ten Cycles of Rework; Internal Connection Not Degraded (Polaroid) . . . . . . . . . . . . .

Second Example of PTH Damage During Ten Cycles of Rework; Internal

Connection Not Degraded (Polaroid) . . . .

A-1 Solder Wick Technique. . . . . . . . . .

Vacuum Extraction Technique. . . . . . . . .

A-3 Proper Application of Solder Wick. . . . . .

Proper Vacuum Extraction Tip-Joint Combination. . . . . . . . . . . . . .

Elimination of Sweat Joints by Agitating Component Leads. . . . . . . . . . .

Temperature Profiles of PTHs Reworked by Vacuum Extraction . . . . . . . . . . .

Temperature Profiles of PTHs Reworked by Solder Wick . . . . . . . . . . . . . . . 


\section{TABLES}

Number

1

2

3

4

5

6

7
Group 1 Statistics. . . . . . . . . . .

Rework Schedule for Group 1 Assemblies. . .

Damage Data for Group 1 Assemblies. . . . .

MLPWB Group 2 Data. . . . . . . . . . . .

Group 2 Statistics. . . . . . . . . . .

Rework Schedule for Group 2 . . . . . . .

Resistance Measurements . . . . . . . . .
Page

12

14

15

17

19

21

28 


\section{SUMMARY}

Processes of reworking printed wiring assemblies (PWA) built with multilayer printed wiring boards (MLPWB) were investigated.

Because of the MLPWBs added thickness and increased heat absorption potential, assemblies built with these boards are suspected of being more susceptible to damage during component removal than assemblies built with single-layer double-sided boards. There also have been questions raised about the effect that rework has on the internal connections of the MLPWBs.

A review and limited evaluation of all known rework methods resulted in selecting "solder wick" and "vacuum extraction" as the two main rework methods for use in the evaluations. The Appendix defines and describes these rework techniques.

Two different groups of units, intended to be representative of a wide range of proposed and presently used MLPWB-component configurations, were fabricated and then reworked by variations of these two techniques. Units from the first group of assemblies consisted of a 6-layer mother board with 16 PWAs (11 leads to 32 leads per PWA) mounted vertically to the mother board. The second group of assemblies consisted of 67 units divided into 7 sections by MLPWB type. MLPWB thickness ranged from 0.026 inch $(0.66 \mathrm{~mm})(3$-layer ) to 0.100 inch $(2.54 \mathrm{~mm})(10$-layer) and the plated-thru-hole (PTH) diameters ranged from 0.028 inch $(0.71 \mathrm{~mm})$ to 0.053 inch $(1.35 \mathrm{~mm})$. Each unit contained 81 components (2leaded to 20-leaded) for a total of 271 solder joints per unit. All MLPWBs for this project were fabricated by the standard etchback process used at Bendix.

Approximately 16,000 internal connections of MLPWBs were subjected to rework. No internal connections became open or degraded. In addition, 80 PTHs with internal connections were subjected to 10 cycles of rework to examine the effect of rework on MLPWB internal connections. Continuity of the internal connections was measured before and after all rework. Even though the rework did cause extensive external damage to the MLPWBs (blisters, measles, and land damage, for example), there was no indication of internal connection degradation. The information received thus far leads to the conclusion that internal connections of MLPWBs are not likely to be degraded as a result of assembly rework.

An examination of the rework results of the two assembly groups suggests that the following statements can be made.

Vacuum extraction is the preferred rework technique for removing multileaded components from PTHs. 
Solder wick is the preferred rework technique for removing lap joint solder connections.

- Solder wick and vacuum extraction are equally suitable for removing two and three leaded components.

- MLPWB thickness can limit the use of the solder wick technique.

- The probability of successful component removal is proportional to the number of leads on the component.

- The probability of successful component removal is related to. the tightness of fit between PTH and component lead.

- Internal connections of multilayer boards do not become open as a result of normal assembly rework.

Indications are that certain rework methods yield better results than other methods. It should be emphasized, however, that the experience and training of the person performing the rework may be at least as important as the rework tools used.

Rework results attained so far suggest that, except for board thickness, there is no significant difference between reworking MLPWB assemblies and reworking assemblies built with single-layer double-sided boards. This will be examined further. In addition, future work will concentrate on investigating the operating characteristics and limitations of the solder wick and vacuum extraction rework techniques. 


\section{DISCUSSION}

SCOPE AND PURPOSE

Multilayer printed wiring boards are becoming widely used in the printed wiring assemblies of electronic products manufactured at Bendix Kansas City. Increased circuit complexity and miniaturization of packaging technology has resulted in the need to efficiently interconnect multileaded components by using multilayer boards with up to 8 or 10 layers. Rework of a printed wiring assembly (PWA) may be required because of a defective component, a manufacturing error, a design change, or a component-board solderability problem. More heat is usually required to rework a multilayer printed wiring board (MLPWB) assembly because the MLPWB is thicker than the single layer board and its internal conductors can have the effect of a heat sink.

This process development project investigates the effectiveness of several commonly used techniques for reworking assemblies containing proposed and presently used MLPWB-component configurations. The work is directed toward resolving two areas of concern: what effect does assembly rework have on the internal connections of multilayer boards, and what are the most effective techniques for specific rework situations. The term rework, as used in this project, refers to the removal of soldered-in components from nonencapsulated printed wiring board assemblies.

\section{PRIOR WORK}

Much of the investigative work on PWA rework has been performed by the manufacturers of rework equipment. Their studies and reports tend to be directed to rework situations specifically suited to the use of their equipment.

\section{ACTIVITY}

To accomplish the desired rework investigations, two different groups of multilayer board assemblies were built and reworked by several different techniques. In addition to the assembly rework, special evaluations were conducted to determine the temperature characteristics of different rework techniques and to determine the integrity of MLPWB internal connections before and after rework. 
Rework Techniques

There are many different rework methods and variations of methods for component solder joint removal. Rework methods reviewed and considered for this project include solder wick, mechanical solder sucker, iron heat and pull, wave heat and pull, heat and shake, vacuum extraction, and heat and forced exhaust.'

After examining and performing preliminary evaluations of these rework techniques it was decided to use two variations of the solder wick method and two variations of the vacuum extraction method for most of the evaluations of this project. The other repair techniques were found to be somewhat ineffective, cumbersome, or damaging. The Appendix discusses the limitations and proper application of these two rework methods.

Assembly Group 1

Figures 1 and 2 show a unit from Group 1 . Table 1 gives statistical information on the units in this group. Units in Group 1 consisted of a 6-layer mother board with 16 PWAs mounted vertically to the mother board. All units were identical with the exception that three units contained solder dipped and leveled PWBs and four units contained non-leveled tin-lead electroplated PWBs. Rework of this group of seven units was intended to simulate difficult multileaded component rework situations such as unit dissassembly, PWA removal, terminal-header removal, and integrated circuit removal.

One unit of the Group 1 assemblies was reworked by a variation of the wave heat and pull technique and the remaining rework was done by the solder wick and vacuum extraction techniques.

The wave heat and pull rework method was found to be unacceptable. The procedure was to heat all solder joints of the mother board simultaneously and then lift the PWAs off the board. Simultaneous heating of all solder joints was accomplished with a Zeva Model TSM 9/FT Drag Soldering System. The basic problem with applying the wave heat and pull technique to reworking a Group 1 assembly is that there is usually sufficient interference between the leads and plated-thru-holes to cause stress on the mother board when an attempt is made to lift the PWA. The combination of stress and high temperature can result in blisters and delamination $^{1}$ of the multilayer mother board. Figure 3 shows a MLPWB blister area which occurred during PWA removal by this rework method.

Table 2 lists the schedule for the Group 1 units reworked by the solder wick and vacuum extraction methods. A total of 96 PWAs (1770 plated-thru-holes) were reworked by these techniques. All 


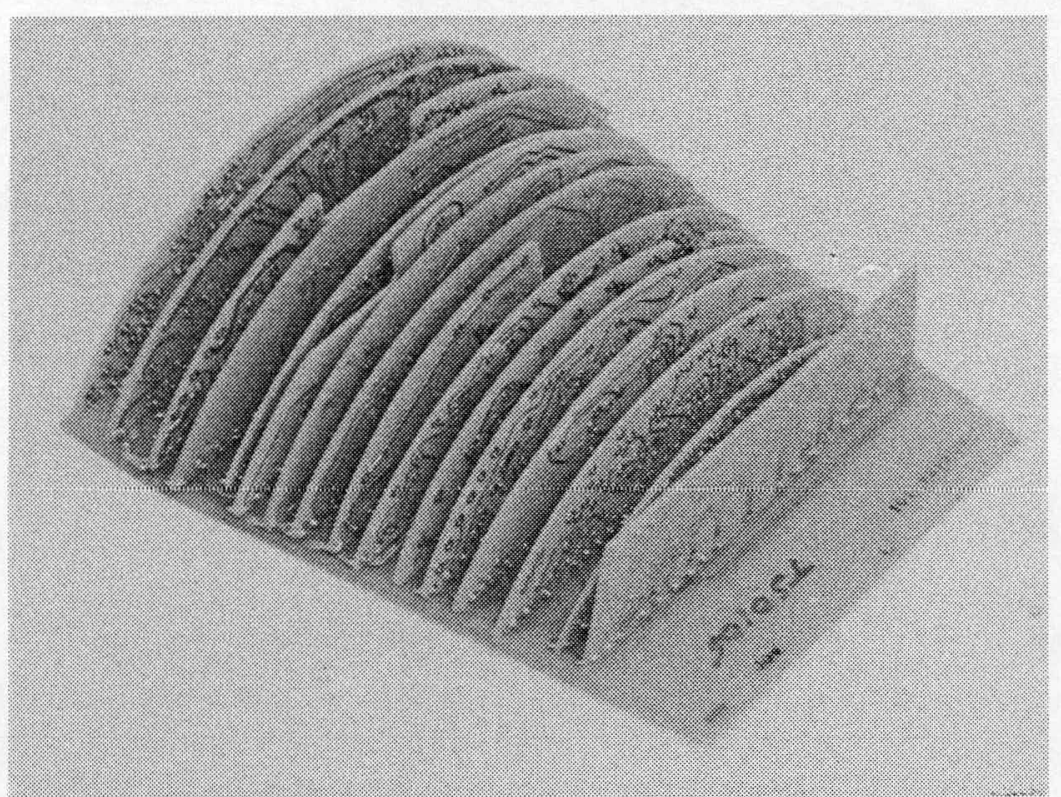

Figure 1. Overall View of a Group 1 Assembly

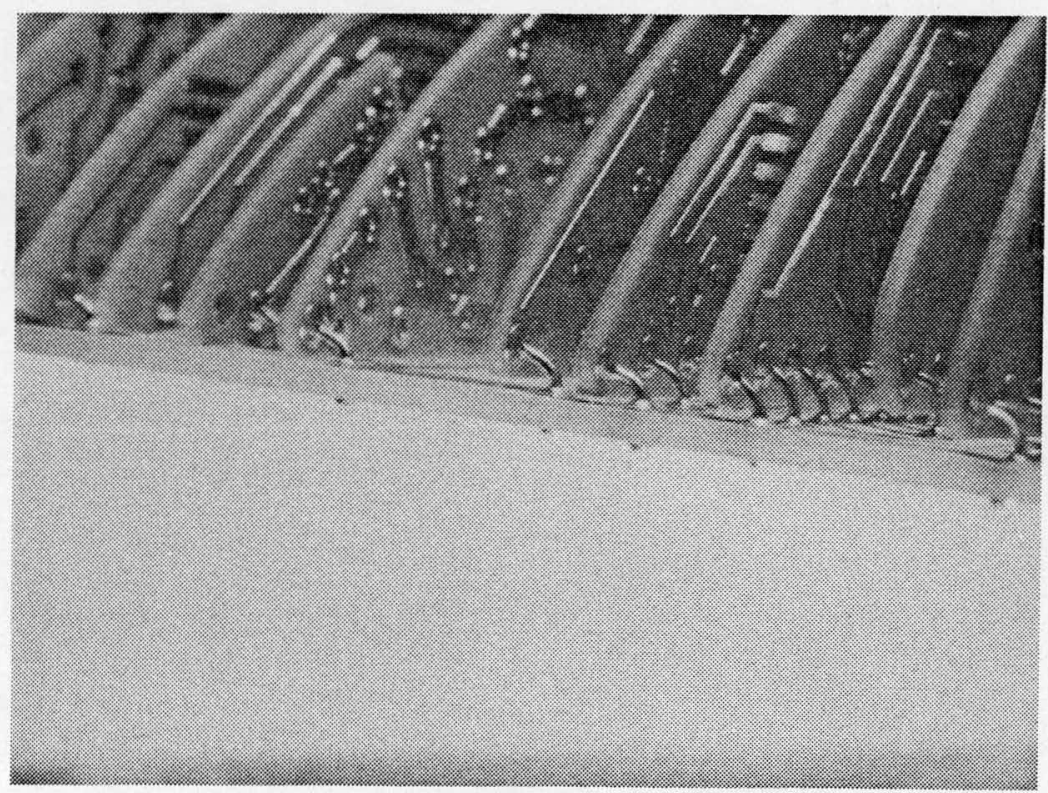

Figure 2. Close-Up View of a Group 1 Assembly Showing Connection of PWAs to Multilayer Mother Board 
Table 1. Group 1 Statistics

\begin{tabular}{lcc}
\hline PWA & $\begin{array}{l}\text { Number of } \\
\text { Plated-Thru } \\
\text { Row* }\end{array}$ & $\begin{array}{l}\text { Number of } \\
\text { Internal } \\
\text { Connections }\end{array}$ \\
\hline 1 & 17 & 14 \\
2 & 11 & 10 \\
3 & 18 & 23 \\
4 & 13 & 11 \\
5 & 24 & 15 \\
6 & 12 & 9 \\
7 & 12 & 13 \\
8 & 18 & 22 \\
9 & 19 & 11 \\
10 & 22 & 24 \\
11 & 32 & 6 \\
12 & 26 & 16 \\
13 & 15 & 3 \\
14 & 12 & 27 \\
15 & 24 & 223 \\
16 & 20 & \\
Total & 295 & \\
& & \\
\hline *PWA & lead diameter is Number 24 AWG \\
* * Plated-thru holes & range from \\
0.025 & inch (0.635 mm) & to 0.065 inch \\
(1.65 mm) & \\
\hline
\end{tabular}

vacuum extraction rework was performed with a Pace, Model SX300, Sodr-X-Traction System. (Pace Incorporated, Silver Spring, MD). The majority of the printed wiring board damage incurred during rework was in the categories of measles and scratches. ${ }^{1}$ No internal connection of a MLPWB became open as a result of the rework. Table 3 lists the incidence and type of damage for each rework technique used on the Group 1 assemblies. The vacuum extraction method resulted in significantly less rework damage than the solder wick method. Figure 4 shows a "worst case" comparison of the two techniques.

The vacuum extraction method was also found to be the faster of the two. All operators reported this method to be approximately twice as fast as the solder wick method. This is not considered especially significant, however, since minimizing damage during rework is much more important in most cases than the speed of rework. 


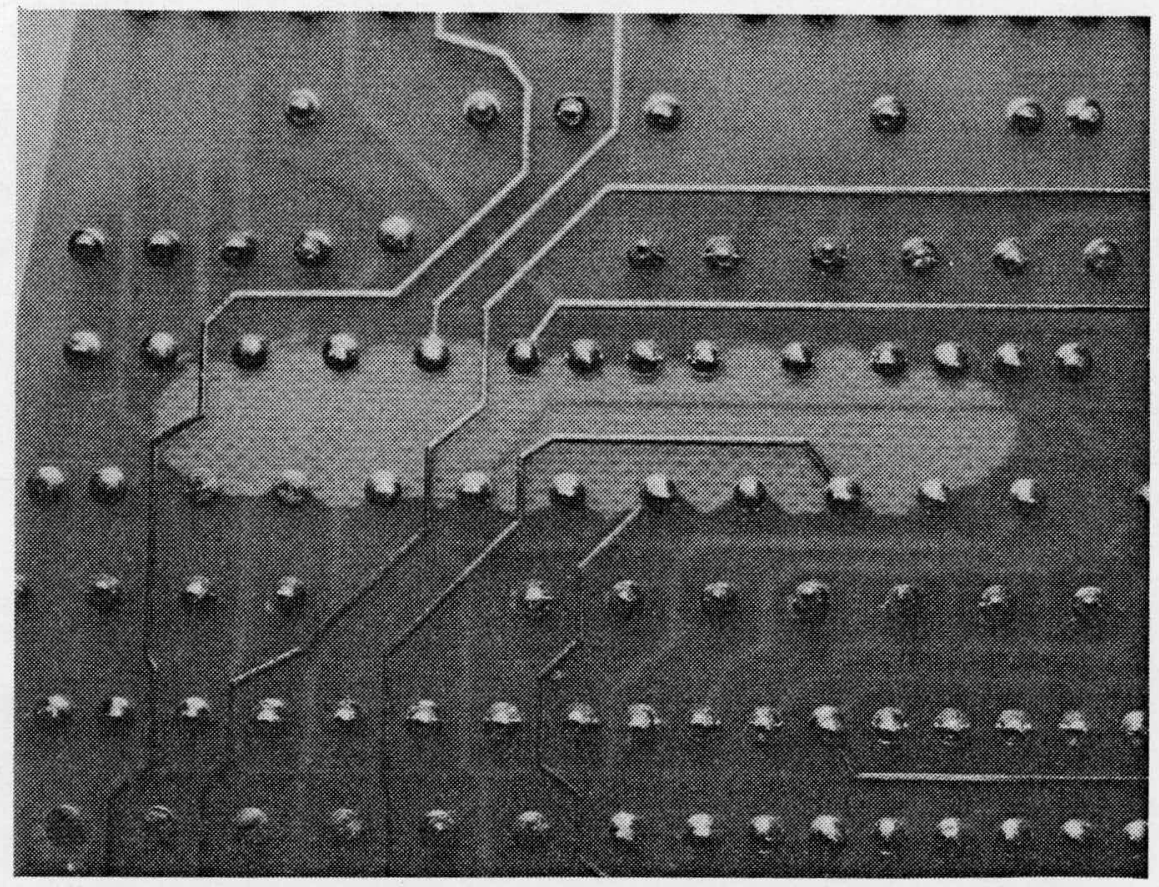

Figure 3. Blister Caused by Wave Heat and Pull Technique

Assembly Group 2

Assembly Group 2 consisted of a total of 67 units divided into 7 different sections by MLPWB type. The same hole and circuit pattern was used on all MLPWBs but the boards varied in hole size, number of internal layers, thickness, and fabrication process. Table 4 defines the seven types of MLPWBs used. Figure 5 shows a unit from Group 2. Table 5 gives statistical information on the units in this group.

The cumulative rework of the Group 2 assemblies consisted of removing 5,427 components $(18,157$ solder joints) from 6 , 8 , and 10-layer MLPWBs approximately 0.026 inch $(0.66 \mathrm{~mm})$ to 0.101 inch $(2.57 \mathrm{~mm})$ thick. The number of component leads ranged from 2 to 20 and the diameter ratio of the PTH to component lead was 1.08 to 3.27 .

All rework on the Group 2 assemblies, except for one component, was performed by variations of the solder wick and vacuum extraction methods. Vacuum extraction rework was performed with a Pace Model SX300 Sodr-X-Traction System and a Weller Model DS100 Power Desoldering Station. Table 6 lists the rework schedule, by technique, for Group 2. 
Table 2. Rework Schedule for Group 1 Assemblies

\begin{tabular}{llll}
\hline Vacuum Extraction & Solder Wick $\ldots$ \\
\hline $0101-01 *$ & $0101-03$ & $0101-02$ & $0101-04$ \\
$0101-05$ & $0101-07$ & $0101-06$ & $0101-08$ \\
$0101-09$ & $0101-11$ & $0101-10$ & $0101-12$ \\
$0101-13$ & $0101-15$ & $0101-14$ & $0101-16$ \\
$0102-02$ & $0102-04$ & $0102-01$ & $0102-03$ \\
$0102-06$ & $0102-08$ & $0102-05$ & $0102-07$ \\
$0102-10$ & $0102-12$ & $0102-09$ & $0102-11$ \\
$0102-14$ & $0102-16$ & $0102-13$ & $0102-15$ \\
$0106-01$ & $0106-03$ & $0106-02$ & $0106-04$ \\
$0106-05$ & $0106-07$ & $0106-06$ & $0106-08$ \\
$0106-09$ & $0106-11$ & $0106-10$ & $0106-12$ \\
$0106-13$ & $0106-15$ & $0106-14$ & $0106-16$ \\
$101 \mathrm{~A}-01$ & $101 \mathrm{~A}-03$ & $101 \mathrm{~A}-02$ & $101 \mathrm{~A}-04$ \\
$101 \mathrm{~A}-05$ & $101 \mathrm{~A}-07$ & $101 \mathrm{~A}-06$ & $101 \mathrm{~A}-08$ \\
$101 \mathrm{~A}-09$ & $101 \mathrm{~A}-11$ & $101 \mathrm{~A}-10$ & $101 \mathrm{~A}-12$ \\
$101 \mathrm{~A}-13$ & $101 \mathrm{~A}-15$ & $101 \mathrm{~A}-14$ & $101 \mathrm{~A}-16$ \\
$102 \mathrm{~A}-02$ & $102 \mathrm{~A}-04$ & $102 \mathrm{~A}-01$ & $102 \mathrm{~A}-03$ \\
$102 \mathrm{~A}-06$ & $102 \mathrm{~A}-08$ & $102 \mathrm{~A}-05$ & $102 \mathrm{~A}-07$ \\
$102 \mathrm{~A}-10$ & $102 \mathrm{~A}-12$ & $102 \mathrm{~A}-09$ & $102 \mathrm{~A}-11$ \\
$102 \mathrm{~A}-14$ & $102 \mathrm{~A}-16$ & $102 \mathrm{~A}-13$ & $102 \mathrm{~A}-15$ \\
$106 \mathrm{~A}-01$ & $106 \mathrm{~A}-03$ & $106 \mathrm{~A}-02$ & $106 \mathrm{~A}-04$ \\
$106 \mathrm{~A}-05$ & $106 \mathrm{~A}-07$ & $106 \mathrm{~A}-06$ & $106 \mathrm{~A}-08$ \\
$106 \mathrm{~A}-09$ & $106 \mathrm{~A}-11$ & $106 \mathrm{~A}-10$ & $106 \mathrm{~A}-12$ \\
$106 \mathrm{~A}-13$ & $106 \mathrm{~A}-15$ & $106 \mathrm{~A}-14$ & $106 \mathrm{~A}-16$ \\
& & & \\
\hline
\end{tabular}

*The first four digits indicate the assembly serial number; the last two indicate the PWA number.

The most difficult component to remove from the multilayer boards was a 20-leaded header with 0.040 inch $(1.02 \mathrm{~mm})$ diameter pins. The header was soldered in 0.043 inch $(1.09 \mathrm{~mm})$ diameter holes and mounted flush to the board. This rework situation is expected to be much more difficult than most rework cases normally encountered in production. The only successful method found to remove this component was a combination of the vacuum extraction and forced exhaust techniques (Figures 6,7 , and 8 ). 
Table 3. Damage Data for Group 1 Assemblies

\begin{tabular}{|c|c|c|c|c|}
\hline \multirow{2}{*}{$\begin{array}{l}\text { Assembly } \\
\text { Serial } \\
\text { Number. }\end{array}$} & \multicolumn{2}{|c|}{$\begin{array}{l}\text { Measles and Scratches } \\
\text { (Defects/PTHs) } \ldots\end{array}$} & \multicolumn{2}{|c|}{$\begin{array}{l}\text { Other Damage } \\
\text { (Defects/PTHs) }\end{array}$} \\
\hline & $\begin{array}{l}\text { Vacuum } \\
\text { Extraction }\end{array}$ & $\begin{array}{l}\text { Solder } \\
\text { W.ick }\end{array}$ & $\begin{array}{l}\text { Vacuum } \\
\text { Extraction }\end{array}$ & $\begin{array}{l}\text { Solder } \\
\text { Wi.ck }\end{array}$ \\
\hline 0101 & $23 / 159$ & $66 / 136$ & $0 / 159$ & $0 / 136$ \\
\hline 0102 & $26 / 136$ & $78 / 159$ & $0 / 136$ & $0 / 159$ \\
\hline 0106 & $13 / 159$ & $71 / 136$ & $0 / 159$ & $0 / 136$ \\
\hline $101 \mathrm{~A}$ & $12 / 159$ & $24 / 136$ & $2 / 159$ & $1 / 136$ \\
\hline $102 \mathrm{~A}$ & $15 / 136$ & $27 / 159$ & $0 / 136$ & $8 / 159$ \\
\hline $106 \mathrm{~A}$ & $19 / 159$ & $32 / 136$ & $0 / 159$ & $0 / 136$ \\
\hline Totals & $108 / 908$ & $298 / 862$ & $2 / 908$ & $9 / 862$ \\
\hline
\end{tabular}

Measles and scratches were by far the most common type of damage during rework of the Group 2 assemblies. Out of approximately 18,000 reworked solder connections there were 1,562 cases of PWB surface damage of which 88.6 percent were scratches or measles. The remaining damage consisted of blisters, burn spots, and land damage. ${ }^{1}$ There were no cases of a MLPWB internal connection becoming open or degraded. Correlation of the rework damage (unless stated otherwise, rework damage refers to measles and scratches) with the rework techniques and rework situations yields the following statements.

Number of Component Leads: As would have been expected, the chances of damaging the MLPWB during removal of a component increases as the number of component leads increases. The plot of Figure 9 demonstrates this correlation on the rework of the Group 2 assemblies. This plot presents the averaged distribution of results for all units and all rework techniques.

PTH and Component Lead Diameters: Rework results indicate a correlation of the probability of rework damage with the "tightness-of-fit" of the lead-hole pair. The relative size of the component lead or MLPWB hole was not found to be important (no correlation with occurrence of rework damage). Figure 10 is a plot of the average occurrence of rework damage versus the difference in cross section area of the lead-hole pairs for the Group 2 assemblies.. The plots 


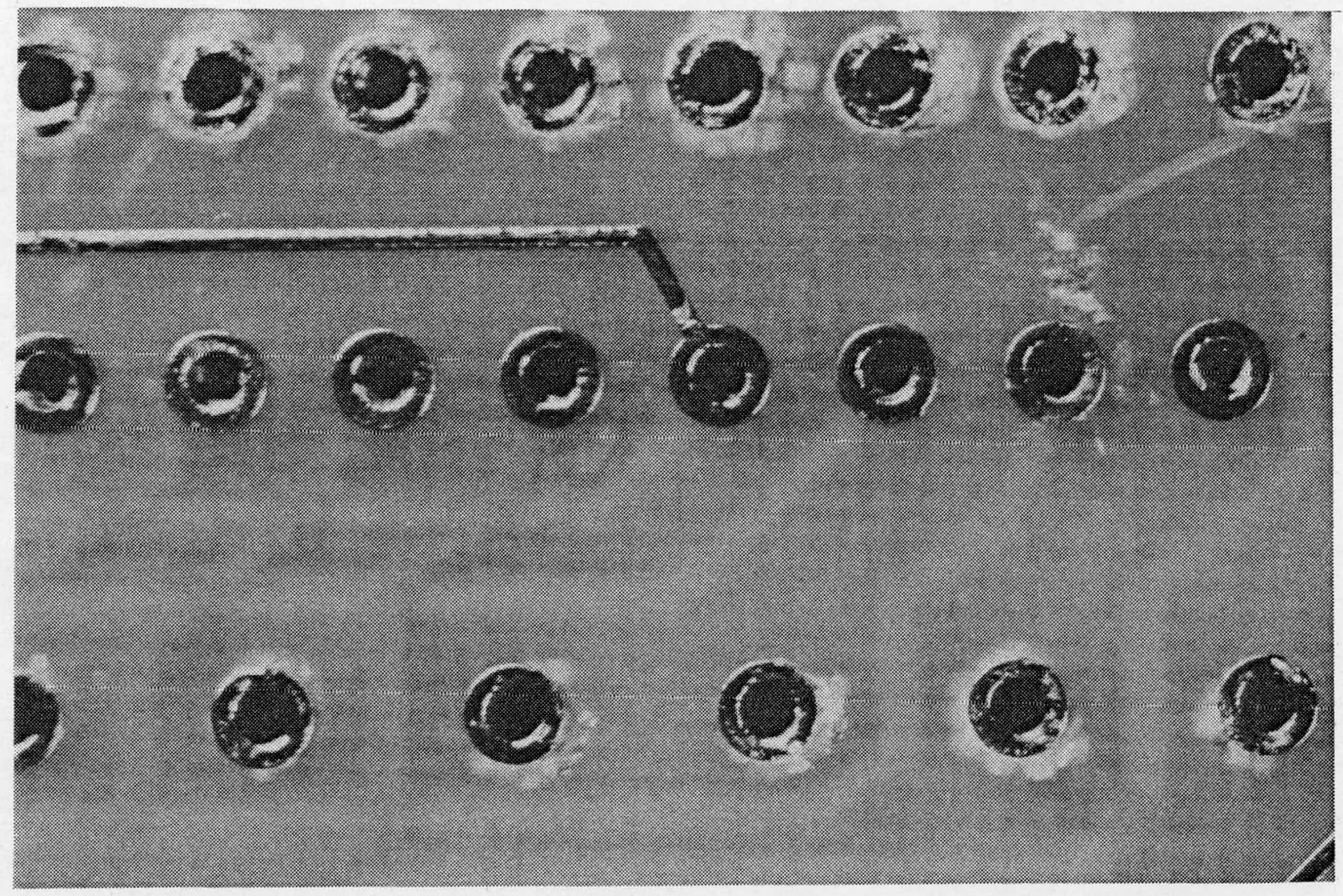

Figure 4. "Worst Case" Comparison of Vacuum Extraction and Solder Wick Techniques (Top and Bottom Rows Show Solder Wick; Middle Row Shows Vacuum Extraction)

indicate that when the "area difference" decreases below approximately $300\left(10^{-6}\right)$ square inches $\left(0.194 \mathrm{~mm}^{2}\right)$ the occurrence of damage significantly increases.

- MLPWB Fabrication Process: There was no difference in the rework results for solder dipped and leveled MLPWBs and tin-lead electro-plated MLPWBs.

- MLPWB Thickness: The plot of Figure 11 shows the occurrence of rework damage versus board thickness. MLPWB thickness has been found to be a limitation in the application of the solder wick method. The capillary action of solder wick was not great enough to successfully rework the assemblies built with the thick Type 5 MLPWB (10 layers, 0.100 inch $(2.5 \mathrm{~mm}$ ) thick). In addition, the solder wick rework method produced a significant amount of rework damage (in the form of measles) on the assemblies built with the thin Type 3 and Type 4 MLPWBs ( 3 layers, 0.026 and 0.036 inch $(0.66$ and $0.91 \mathrm{~mm}$ ) 
Table 4. MLPWB Group 2 Data

\begin{tabular}{|c|c|c|c|c|c|}
\hline \multirow[b]{3}{*}{ Subgroup. } & \multirow[b]{3}{*}{ Layers } & & & \multicolumn{2}{|l|}{ Processing: } \\
\hline & & \multicolumn{2}{|c|}{ Thickness } & \multirow{2}{*}{$\begin{array}{l}\text { Tin-Lead } \\
\text { Electroplate }\end{array}$} & \multirow{2}{*}{$\begin{array}{l}\text { Solder } \\
\text { Dipped } \\
\text { Levelled }\end{array}$} \\
\hline & & in. & $\mathrm{mm}$ & & \\
\hline I & $8 *$ & $(0.076)$ & $(1.93)$ & $\mathrm{x}$ & \\
\hline I I & 8 & $(0.072)$ & $(1.83)$ & & $\mathrm{x}$ \\
\hline I I I & 6 & $(0.026)$ & $(0.66)$ & $\mathrm{x}$ & \\
\hline IV & 6 & $(0.036)$ & $(0.91)$ & & $x$ \\
\hline $\mathrm{V}$ & 10 & $(0.101)$ & $(2.57)$ & $\mathrm{x}$ & \\
\hline VI & $8 *$ & $(0.076)$ & $(1.93)$ & $\mathrm{x}$ & \\
\hline VII & 8 & $(0.072)$ & $(1.83)$ & & $\mathrm{x}$ \\
\hline
\end{tabular}

thick). This can probably be partially explained by the large temperature profile of solder wick (Appendix). Board thickness was not found to be a significant factor in the occurrence of rework damage for the vacuum extraction method. With other rework factors constant, the amount of heat required to remove a component from a MLPWB is proportional to the thickness of the board. This must be considered when adjusting the operating temperature of the rework tools regardless of the rework technique being used.

- Rework Technique: The two basic rework methods used on the Group 2 assemblies were solder wick and vacuum extraction. Two different techniques of application were tried: remove the component lead by heating the solder joint with a soldering iron and then remove the solder from the PTH by solder wick or vacuum extraction, and remove the solder from the PTH by solder wick or vacuum extraction and then lift the component lead from the PTH. There was no noted difference in the occurrence of rework damage for the different techniques of application; however, the second technique (remove solder before component lead) is preferred. The first technique (remove component lead before solder) tends to be impractical for removing components with more than three leads, unnecessarily bend and stress component leads, and result in an 


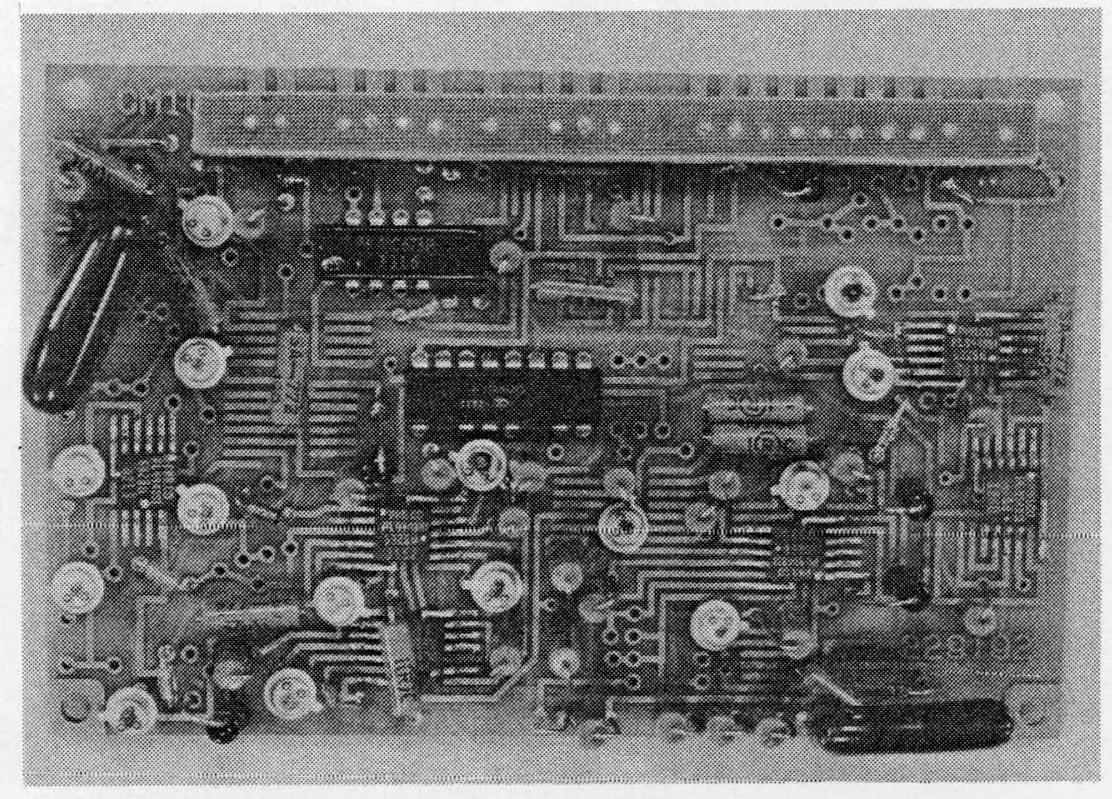

Figure 5. Overall View of Group 2 Assembly

intermediate concave solder joint which is difficult to heat for removal.

An evaluation of the rework results indicates that the following rework technique to component removal assignments can be made.

- Solder wick is the preferred method to remove components connected to the PWB with a lap joint of the solder-reflow type (Figure 12).

- Solder wick and vacuum extraction are equally suitable for removing two and three leaded components.

- The vacuum extraction method is best for removing components with more than three leads. The ability to eliminate residual sweat joints (Figure 13) is the important factor in multileaded component removal. Figures 14 and 15 illustrate vacuum extraction in removing a 16-leaded dual-in-line integrated circuit package.

\section{Internal Connections}

The results of evaluations performed on this project indicate that normal rework of MLPWB assemblies does not have a detrimental effect on the internal connections of multilayer boards. There have been no cases of an internal connection of a multilayer board becoming open or degraded throughout all the assembly rework. 
Table 5. Group 2 Statistics

\begin{tabular}{lcl}
\hline $\begin{array}{l}\text { MLPWB } \\
\text { Subgroup }\end{array}$ & Quantity* & $\begin{array}{l}\text { Serial Number } \\
\text { Identification }\end{array}$ \\
\hline I & 9 & $112-116 ; 118-121$ \\
II & 11 & $201-209,211,212$ \\
III & 10 & $301,304-312$ \\
IV & 6 & $401,403-405,407$, \\
V & 10 & 409 \\
VI & 12 & $501-510$ \\
VII & 9 & $601-612$ \\
& & $701,703,705$, \\
\hline
\end{tabular}

*Each assembly had 207 PTH solder joints, 64 lap solder joints, 53 two-leaded components (diodes resistors, capacitors), 19 three-leaded transistors, one 8-leaded DIP, one 16-leaded DIP, one 20-leaded header, and six 14-leaded flat pack integrated circuits.

The rework of the Group 1 and Group 2 assemblies resulted in approximately 16,000 internal connections (internal path to PTH) being subjected to rework (component lead removed from PTH). All internal connections were verified acceptable before and after rework using the recommended electrical test method. ${ }^{2}$ After completion of the rework of the Group 1 assemblies, the MLPWBs from that group were subjected to 10 temperature cycles in accordance with MIL-STD-202E, Method 102A, Test Condition C. The continuity of all internal connections remained intact and gave no indication of being degraded after temperature cycling.

In addition to the rework of the Group 1 and Group 2 assemblies, a separate evaluation was performed for the purpose of investigating the effect of assembly rework on MLPWB internal connections. The evaluation was based on the performance of 80 internal connections on 10 different MLPWBs when subjected to 10 cycles of rework. The test procedure was as follows.

1. Solder components into the PTHs of the MLPWBs. 


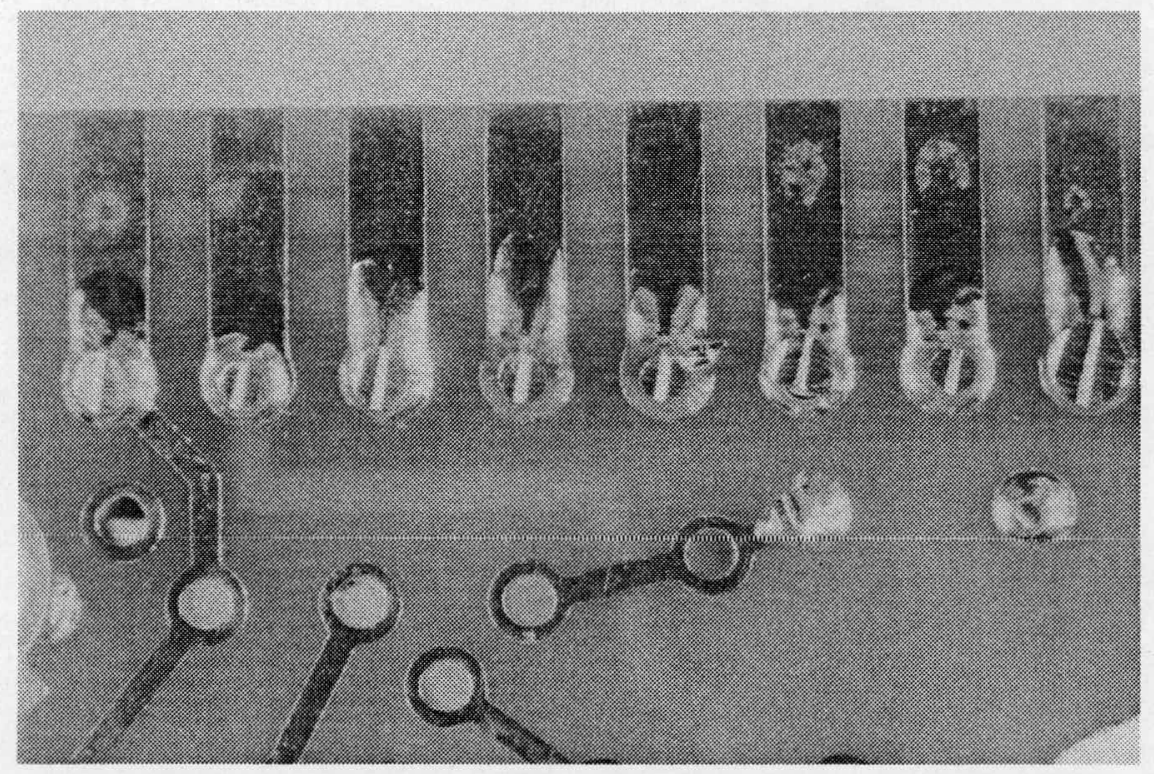

Figure 6. Header Terminal Area Before Rework At tempt

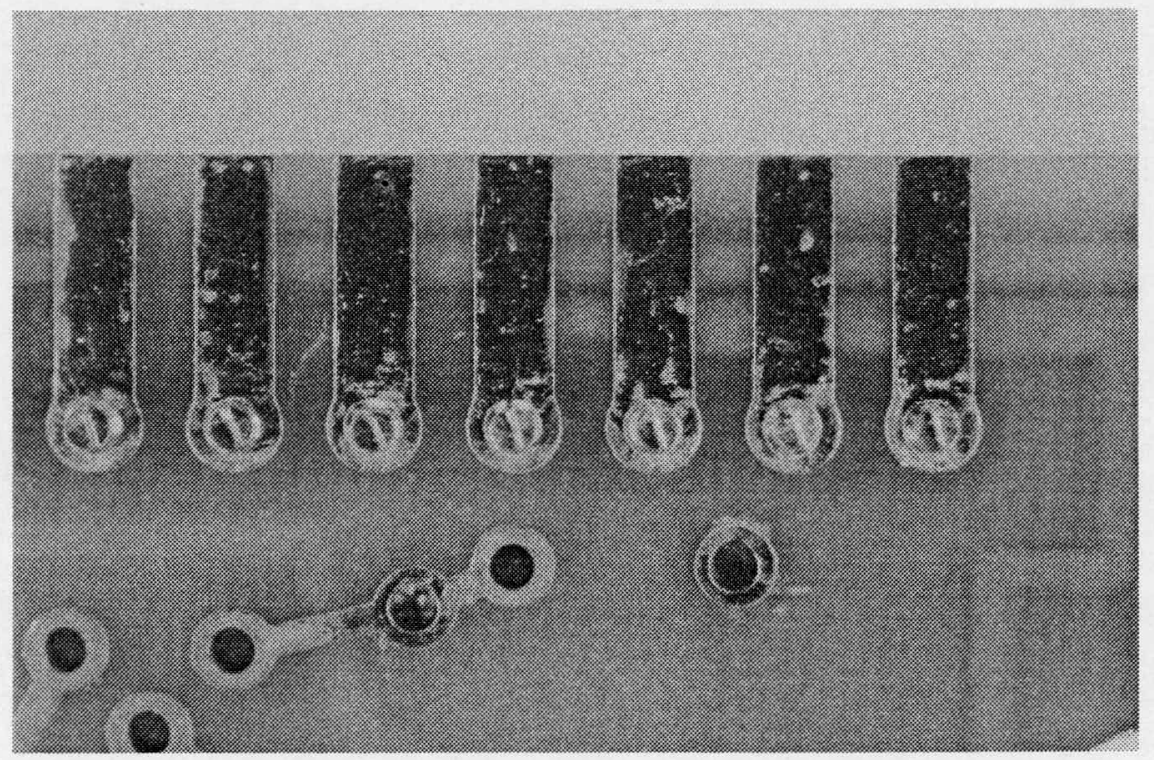

Figure 7. Header Terminal Area After Vacuum Extraction; Sweat Joints Remain Between PTHs and Pins 
Table 6. Rework Schedule for Group 2

\begin{tabular}{ll}
\hline Method & Assembly Serial Numbers \\
\hline Vacuum Extraction* & $116,121,201,205,307$ \\
& $311,407,501,505,601$, \\
Solder Wick & $118,202,206,308,403$, \\
Combination & $506,602,606,610,709$ \\
Heat and Pull and & $114,119,203,207,305$, \\
Vacuum Extraction* & $309,404,503,509,603$, \\
Combination & $115,120,211,306,405$, \\
Heat and Pull and & $508,604,608,612,711$ \\
Solder Wick & $112,209,212,301,312$, \\
Vacuum Extraction** & $409,504,507,703,712$ \\
$\begin{array}{l}\text { Combination } \\
\text { Heat and Pull and }\end{array}$ & $113,204,208,304,310$ \\
Vacuum Extraction** & $401,502,510,701,707$ \\
\hline $\begin{array}{l}\text { *Using Pace Model Sx300 Solder-X-Tractor } \\
\text { * Using Weller Model DS100 PWR Desoldering } \\
\text { Station }\end{array}$ \\
\hline
\end{tabular}

2. Measure the resistance of the continuity loops formed by two PTHs and an interconnecting internal path.

3. Electrically energize the continuity loops measured in Step 2. Figure 16 describes the operation.

4. Repeat the resistance measurements of Step 2.

5. Rework the assemblies using solder wick or vacuum extraction.

6. Repeat Steps 1 thru 5 for 10 cycles.

The results of the resistance measurements are shown in Table 7 . No internal connections became open or gave any indication of being degraded even though there was extensive external physical damage to the boards. Figures 17 and 18 show some of the worst damaged PTH areas at the completion of 10 cycles of rework. Even on these PTHs, although there were cases of blisters, torn 


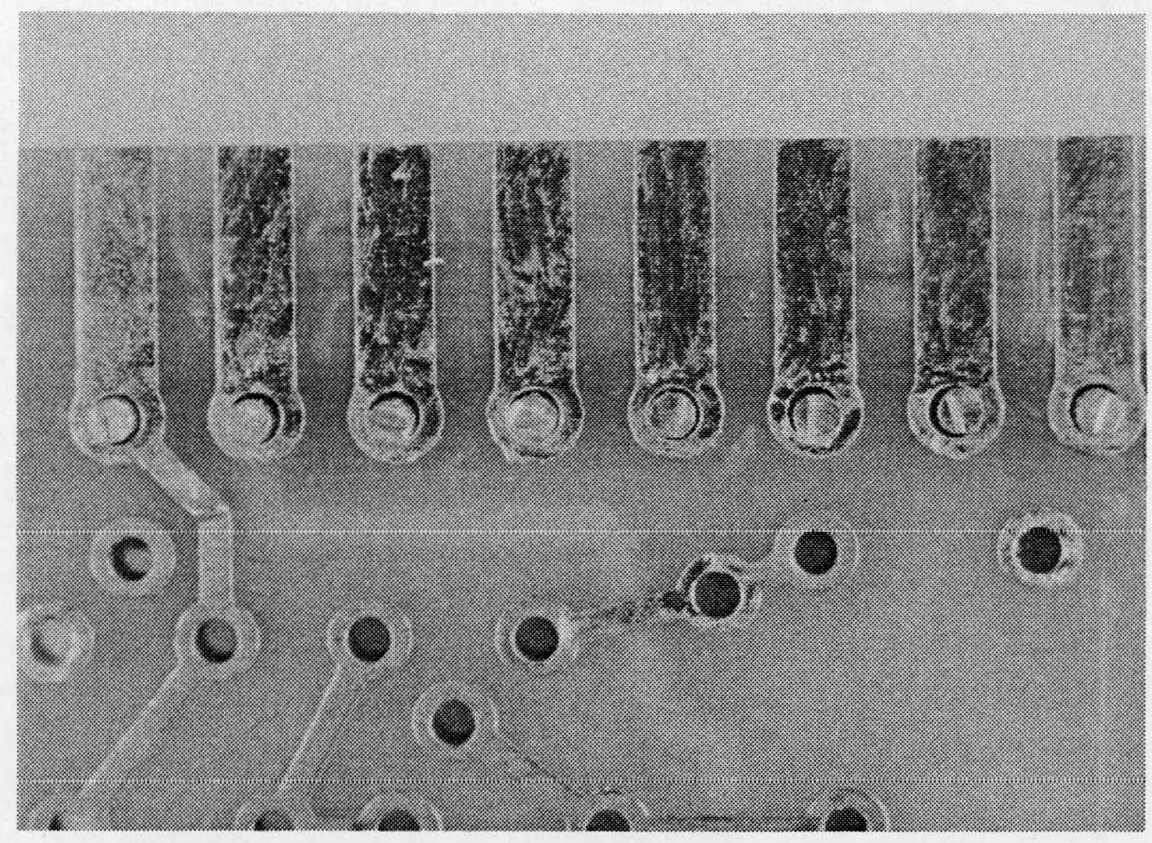

Figure 8. Header Terminal Area After Sweat Joints Removed by Forced Exhaust; Header Can Now Be Lifted Off MLPWB

and removed lands, and so on, there was no indication of a significant change in resistance (continuity) of the internal connections.

\section{Operator Training}

Special rework tools and techniques are not by themselves a guarantee of acceptable rework of MLPWB assemblies. The success of any rework method depends to some extent on the experience and training of the personnel involved. Experience and expertise in soldering and fabrication techniques are valuable for a rework technician; however, personnel should be trained in specific rework tools and procedures to assure successful rework.

\section{ACCOMPLISHMENTS}

The accomplishments and conclusions thus far on this project include the following.

- A significant quantity of rework data (16,000 bits) indicates that the internal connections of multilayer boards are not sensitive to degradation during assembly rework. 


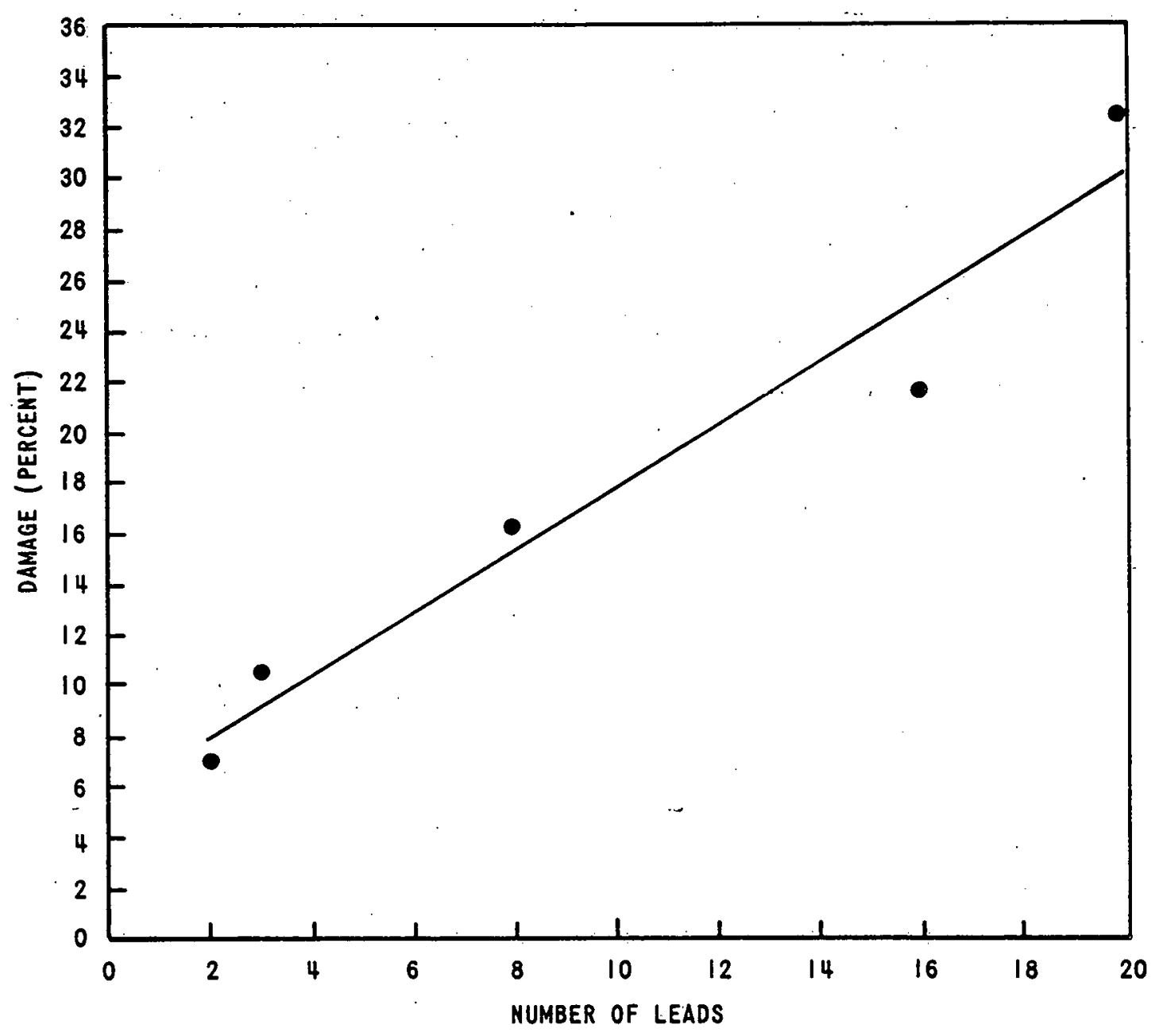

Figure 9. Probability of Damage Versus Number of Component Leads

- An evaluation and review of all known rework techniques has concludéd that two techniques, solder wick and vacuum extraction, are best suited to most rework situations at Bendix Kansas City.

- The solder wick and vacuum extraction methods of rework have been found to be equally effective in successful removal of two and three leaded components.

- Vacuum extraction has been found to be the most efficient and least damaging rework method for removing multileaded (more than three leads) components. 


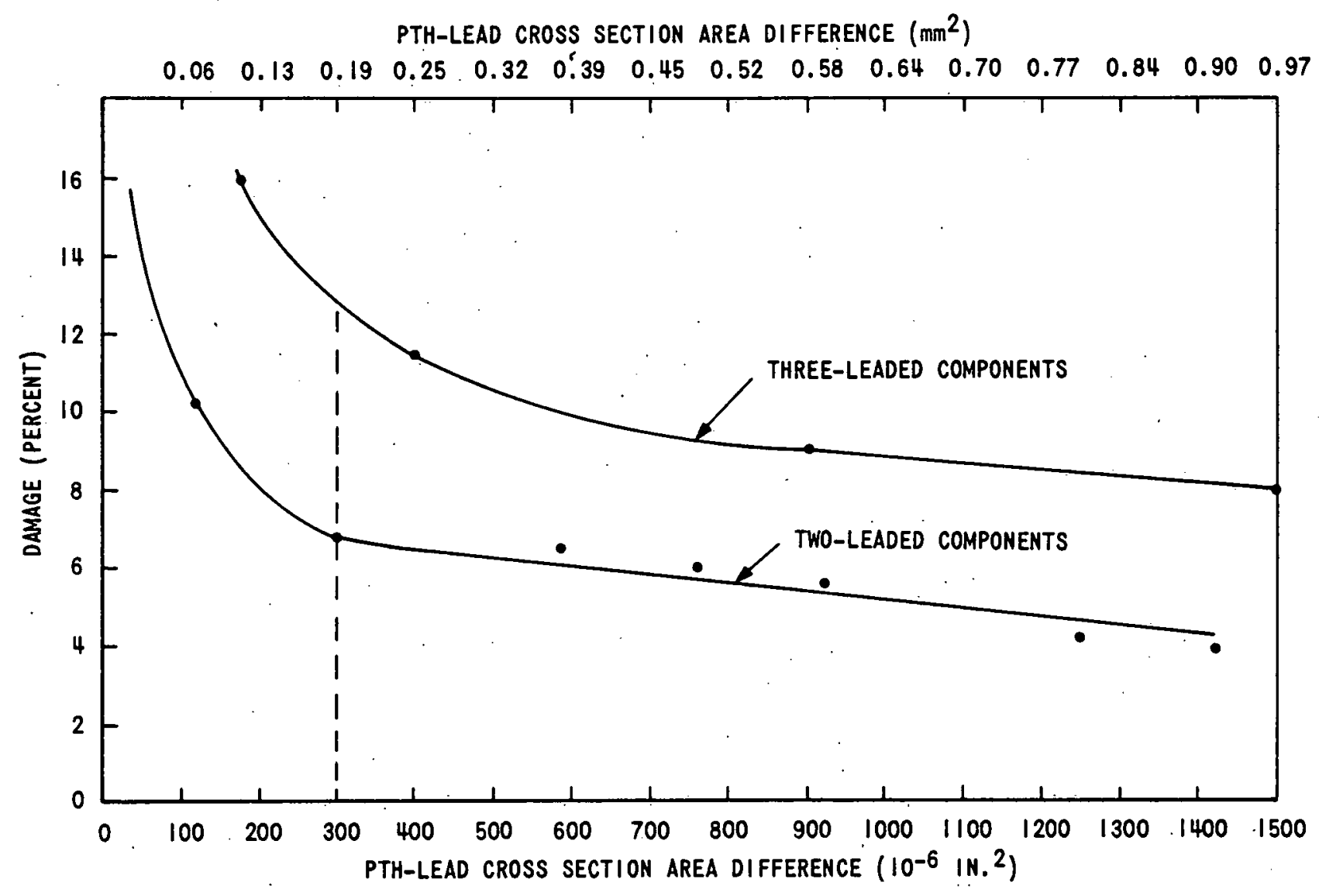

Figure 10. Probability of Damage Versus Tightness of Fit

- It has been verified that, with other rework factors constant, the probability of causing rework damage to a PTH area is proportional to the number of leads on the component associated with that PTH.

- A critical range of tightness of fit for a hole-lead pair has been identified. Below this critical range the probability of rework damage greatly increases.

It was found that MLPWB thickness can be a limitation to the application of the solder wick rework method.

FUTURE WORK

Future work on this project is planned to include the following areas. 


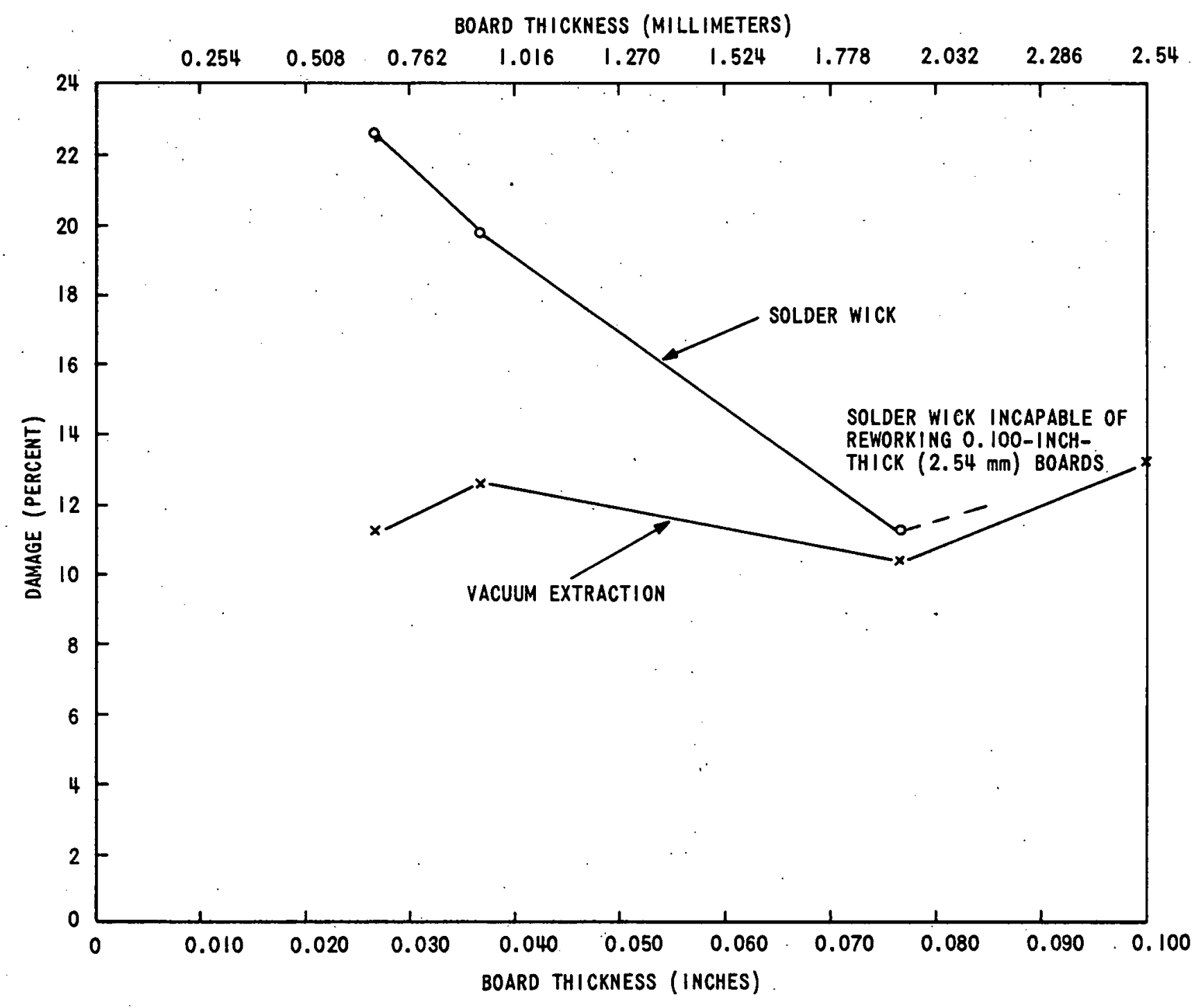

Figure 11. Probability of Damage Versus Board Thickness

- The rework performed thus far indicates that, if board thicknesses are equal, there is no significant difference between reworking assemblies built with MLPWBs and assemblies built with single-layer double-sided boards. This situation will be investigated further.

Solder wick will be examined in an attempt to define the factors (such as PTH diameter, component lead diameter, soldering iron temperature versus wattage, and so on) which limit its application. 


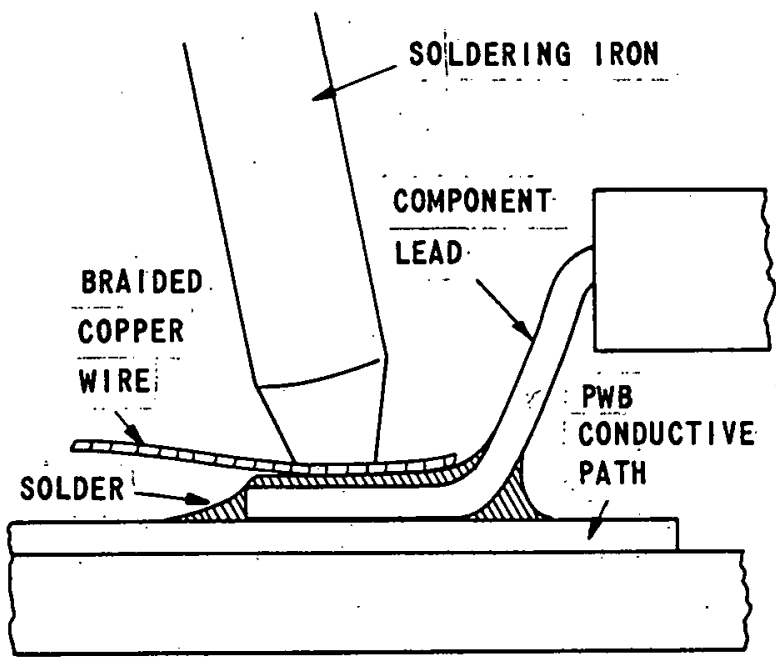

Figure 12. Soldered Lap Joint

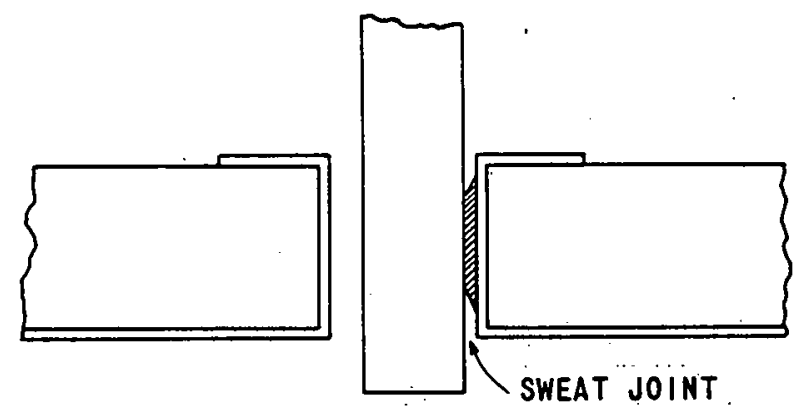

Figure 13.' Soldered Sweat Joint

- Different types of vacuum extraction equipment will be compared for operating characteristics and accessories.

- Evaluations will be conducted to determine the optimum match of extraction tip size with PTH and land size.

- Manufacturing guidelines will be established for reworking printed wiring assemblies. 


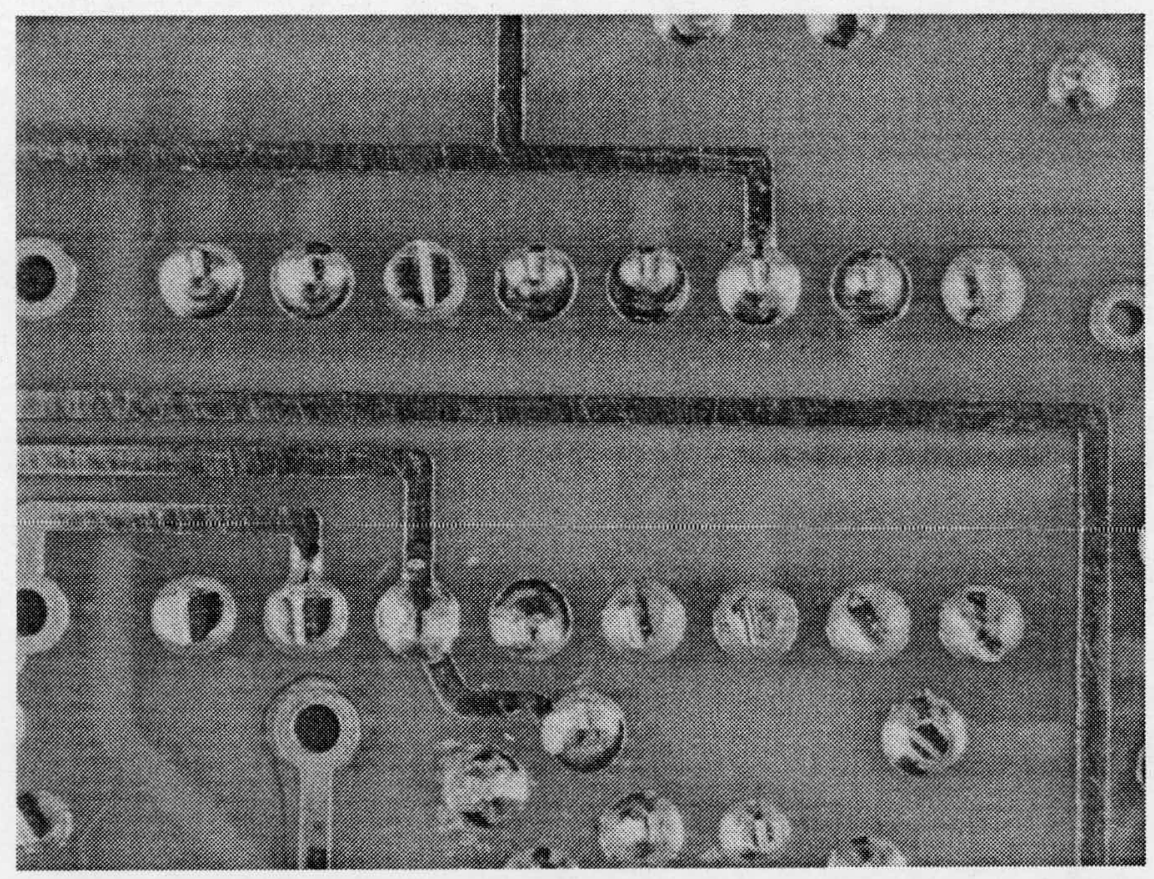

Figure 14. Sixteen Lead DIP Pattern Before Rework by Vacuum Extraction

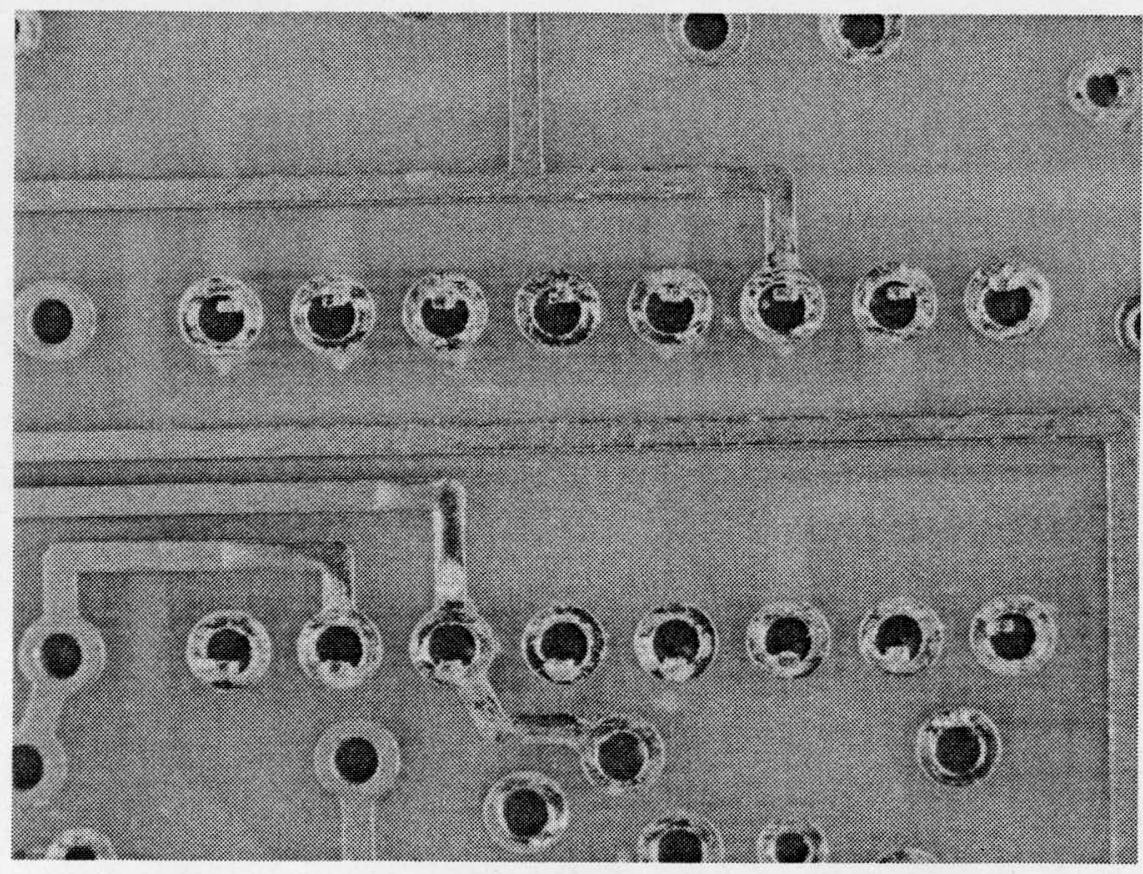

Figure 15. Sixteen Lead DIP Pattern After Solder Removed by Vacuum Extraction; IC Can Now Be Lifted Off MLPWB 


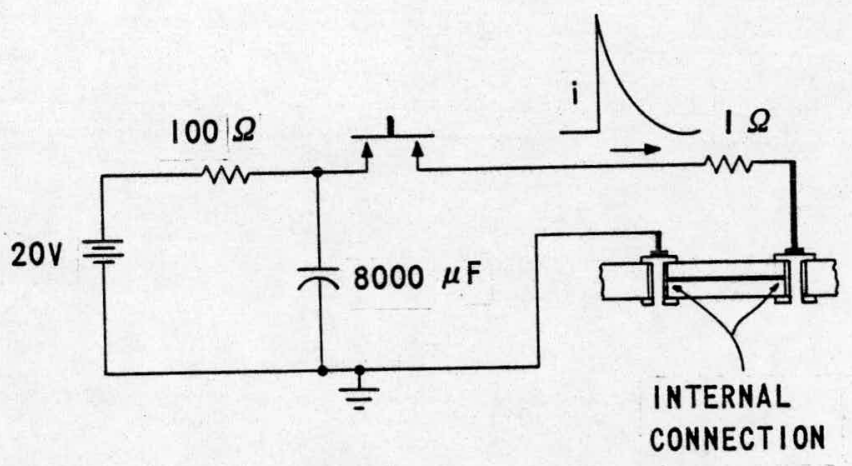

Figure 16. Energizing Circuit

Table 7. Resistance Measurements

\begin{tabular}{|c|c|c|c|c|c|c|}
\hline \multirow{2}{*}{$\begin{array}{l}\text { Serial } \\
\text { Number }\end{array}$} & \multirow{2}{*}{$\begin{array}{l}\text { PTH } \\
\text { Pair } \\
\text { Number }\end{array}$} & \multirow{2}{*}{$\begin{array}{l}\text { Resistance } \\
\text { Comparison } \\
\text { (Percent)* }\end{array}$} & \multicolumn{2}{|c|}{$\begin{array}{l}\text { Highest } \\
\text { Reading }\end{array}$} & \multicolumn{2}{|c|}{$\begin{array}{l}\text { Lowest } \\
\text { Reading }\end{array}$} \\
\hline & & & $\mu \Omega$ & Cycle & $\mu \Omega$ & Cycle \\
\hline TS102 & $\begin{array}{l}1 \\
2 \\
3 \\
4\end{array}$ & $\begin{array}{l}99.26 \\
99.62 \\
99.75 \\
98.77\end{array}$ & $\begin{array}{l}27.2 \\
52.4 \\
40.3 \\
32.6\end{array}$ & $\begin{array}{l}3 \\
5 \\
1 \\
6\end{array}$ & $\begin{array}{l}26.2 \\
51.4 \\
39.1 \\
32.1\end{array}$ & $\begin{array}{l}7 \\
4 \\
8 \\
4,10\end{array}$ \\
\hline TS105 & $\begin{array}{l}1 \\
2 \\
3 \\
4\end{array}$ & $\begin{array}{r}98.23 \\
98.11 \\
101.05 \\
99.38\end{array}$ & $\begin{array}{l}28.3 \\
53.5 \\
38.8 \\
32.8\end{array}$ & $\begin{array}{l}2 \\
3 \\
9 \\
3\end{array}$ & $\begin{array}{l}27.4 \\
51.5 \\
38.0 \\
31.8\end{array}$ & $\begin{array}{l}4,6 \\
2,6 \\
1,8 \\
9\end{array}$ \\
\hline TS106 & $\begin{array}{l}1 \\
2 \\
3 \\
4\end{array}$ & $\begin{array}{l}100.00 \\
100.00 \\
100.00 \\
100.63\end{array}$ & $\begin{array}{l}27.8 \\
53.7 \\
38.6 \\
32.5\end{array}$ & $\begin{array}{l}1,3,5,10 \\
9 \\
7 \\
3\end{array}$ & $\begin{array}{l}27.1 \\
53.1 \\
37.5 \\
31.6\end{array}$ & $\begin{array}{l}8 \\
2 \\
2,6 \\
4\end{array}$ \\
\hline 111 & $\begin{array}{l}1 \\
3 \\
4\end{array}$ & $\begin{array}{r}97.65 \\
98.80 \\
100.83\end{array}$ & $\begin{array}{l}17.4 \\
17.1 \\
12.6\end{array}$ & $\begin{array}{l}3 \\
7 \\
3,7\end{array}$ & $\begin{array}{l}16.5 \\
16.2 \\
12.0\end{array}$ & $\begin{array}{l}2 \\
8 \\
1\end{array}$ \\
\hline 117 & $\begin{array}{l}1 \\
2 \\
3 \\
4\end{array}$ & $\begin{array}{r}102.67 \\
102.00 \\
99.40 \\
97.50\end{array}$ & $\begin{array}{l}16.0 \\
10.7 \\
16.9 \\
12.3\end{array}$ & $\begin{array}{l}6 \\
3 \\
7,9 \\
7\end{array}$ & $\begin{array}{r}15.0 \\
9.5 \\
16.2 \\
11.5\end{array}$ & $\begin{array}{l}1 \\
2 \\
2 \\
2\end{array}$ \\
\hline 122 & $\begin{array}{l}1 \\
3 \\
4\end{array}$ & $\begin{array}{r}101.29 \\
98.23 \\
100.86\end{array}$ & $\begin{array}{l}16.2 \\
17.1 \\
12.5\end{array}$ & $\begin{array}{l}5 \\
5 \\
4\end{array}$ & $\begin{array}{l}15.2 \\
16.2 \\
11.5\end{array}$ & $\begin{array}{l}8 \\
8 \\
1\end{array}$ \\
\hline
\end{tabular}


Table 7 Continued. Resistance Measurements

\begin{tabular}{|c|c|c|c|c|c|c|}
\hline \multirow{2}{*}{$\begin{array}{l}\text { Serial } \\
\text { Number }\end{array}$} & \multirow{2}{*}{$\begin{array}{l}\text { PTH } \\
\text { Pair } \\
\text { Number }\end{array}$} & \multirow{2}{*}{$\begin{array}{l}\text { Resistance } \\
\text { Comparison } \\
\text { (Percent)* }\end{array}$} & \multicolumn{2}{|c|}{$\begin{array}{l}\text { Highest } \\
\text { Reading }\end{array}$} & \multicolumn{2}{|c|}{$\begin{array}{l}\text { Lowest } \\
\text { Reading }\end{array}$} \\
\hline & & & $\mu \Omega$ & Cycle & $\mu \Omega$ & Cycle \\
\hline 210 & $\begin{array}{l}1 \\
2 \\
3 \\
4\end{array}$ & $\begin{array}{r}98.13 \\
100.97 \\
99.39 \\
100.88\end{array}$ & $\begin{array}{l}16.4 \\
10.4 \\
17.0 \\
12.4\end{array}$ & $\begin{array}{l}3,4 \\
10 \\
3 \\
3\end{array}$ & $\begin{array}{r}15.6 \\
9.4 \\
16.1 \\
11.4\end{array}$ & $\begin{array}{l}2,7 \\
8 \\
8 \\
1\end{array}$ \\
\hline 302 & $\begin{array}{l}1 \\
2 \\
3 \\
4\end{array}$ & $\begin{array}{l}102.00 \\
101.96 \\
101.33 \\
100.81\end{array}$ & $\begin{array}{l}15.8 \\
10.4 \\
15.9 \\
13.1\end{array}$ & $\begin{array}{l}3 \\
5,6,10 \\
3 \\
3,6,7\end{array}$ & $\begin{array}{l}15.0 \\
10.0 \\
15.0 \\
12.4\end{array}$ & $\begin{array}{l}1,9 \\
2,9 \\
1 \\
1,2,4\end{array}$ \\
\hline 702 & $\begin{array}{l}1 \\
2 \\
3 \\
4\end{array}$ & $\begin{array}{r}103.89 \\
97.02 \\
100.00 \\
97.56\end{array}$ & $\begin{array}{l}16.2 \\
10.2 \\
17.8 \\
12.9\end{array}$ & $\begin{array}{l}6 \\
1,3,5 \\
9 \\
6\end{array}$ & $\begin{array}{r}15.4 \\
9.2 \\
16.9 \\
12.0\end{array}$ & $\begin{array}{l}1 \\
2 \\
1,10 \\
10\end{array}$ \\
\hline 704 & $\begin{array}{l}1 \\
2 \\
3 \\
4\end{array}$ & $\begin{array}{r}98.73 \\
98.00 \\
103.48 \\
99.19\end{array}$ & $\begin{array}{l}15.9 \\
10.0 \\
17.9 \\
12.7\end{array}$ & $\begin{array}{l}2 \\
1,3,4,5 \\
5,8 \\
8\end{array}$ & $\begin{array}{r}15.4 \\
9.6 \\
17.2 \\
11.5\end{array}$ & $\begin{array}{l}3,8 \\
6,8 \\
1 \\
2\end{array}$ \\
\hline
\end{tabular}




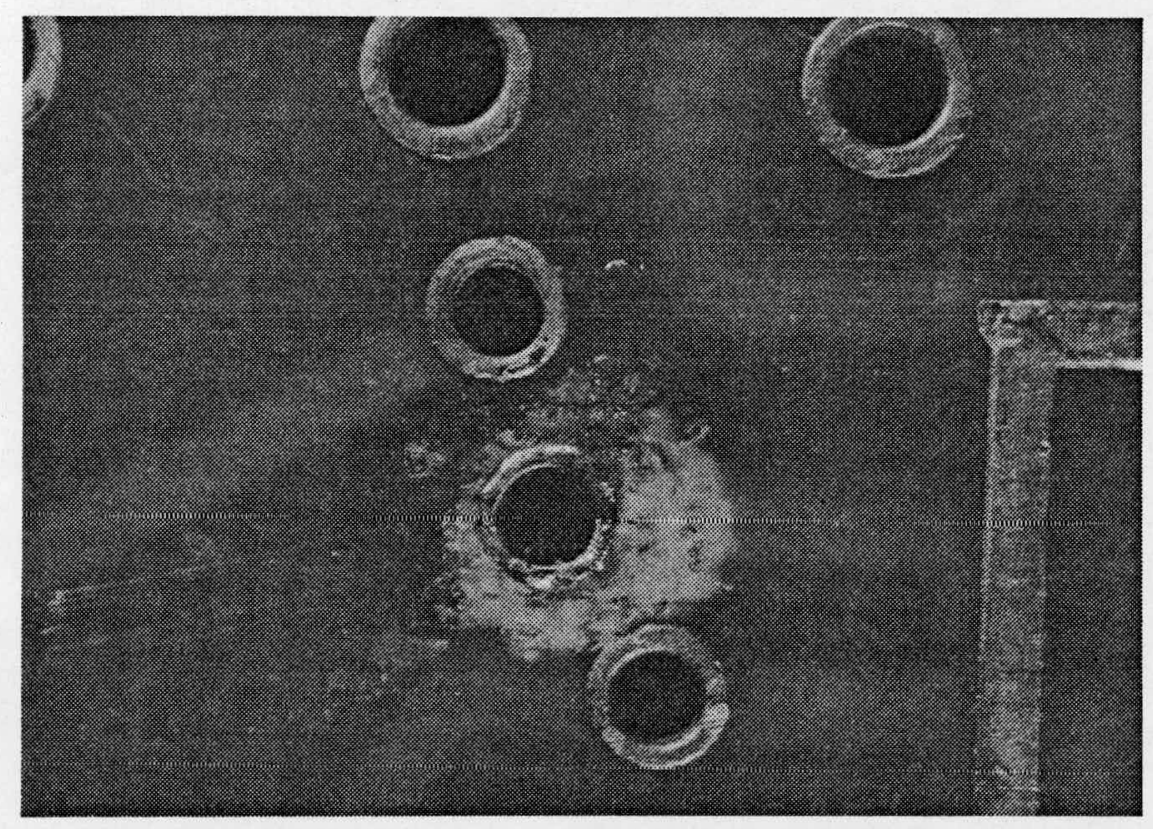

Figure 17. PTH Damaged During Ten Cycles of Rework; Internal Connector Not Degraded

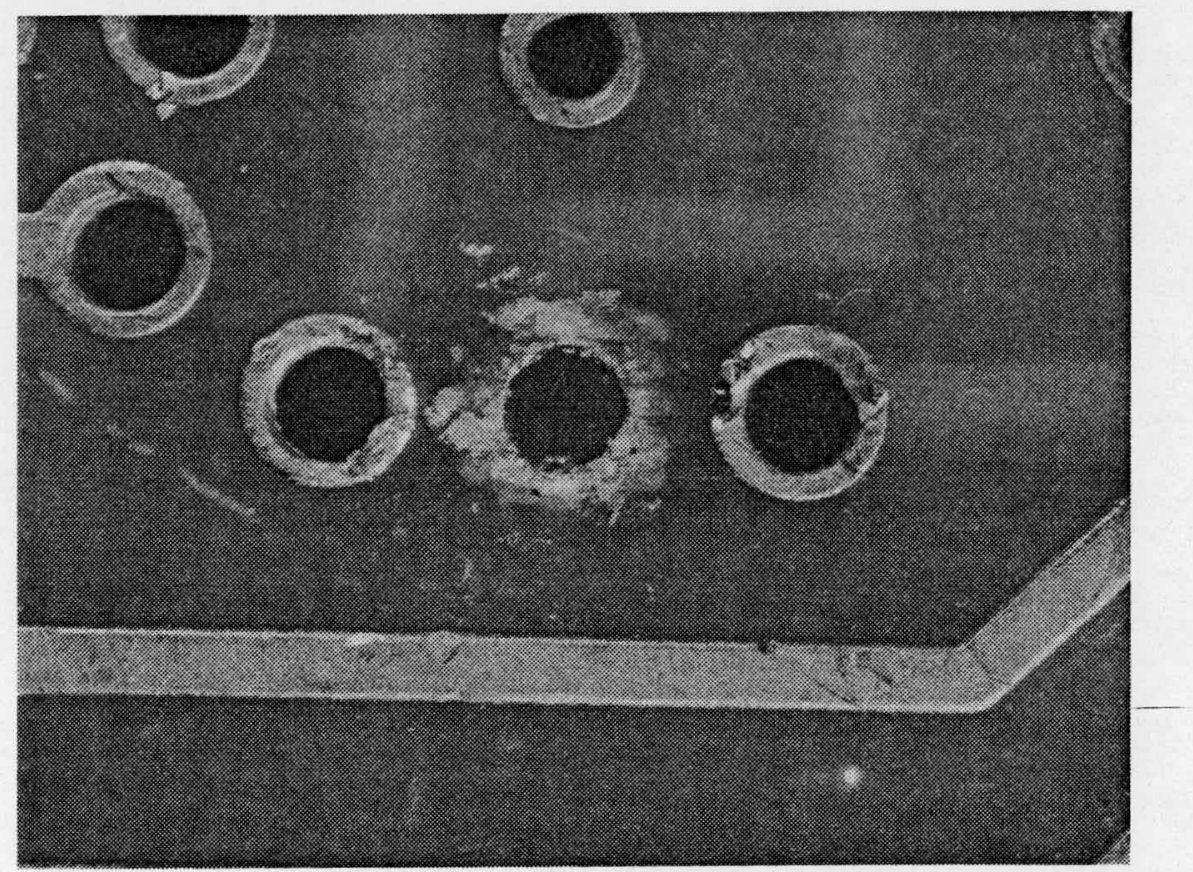

Figure 18. Second Example of PTH Damage During Ten Cycles of Rework; Internal

Connection Not Degraded 


\section{REFERENCES}

${ }^{1} R x$ for Repair and Modification of Printed Wiring Boards, Institute of Printed Circuits, IPC-R-7.00A, Reference Procedure, pp 40-48.

${ }^{2}$ A. D. Andrade, Laboratory Manual: A Fabrication Process for Close-Tolerance, Multilayer Printed Wiring Boards, SCL-DC-67-80, p 27. 
Appendix

APPLICATION OF. THE SOLDER WICK AND

VACUUM EXTRACTION REWORK TECHNIQUES

\section{GENERAL}

\section{Solder Wick}

The solder wick technique is illustrated in Figure A-1. Solder is removed from a solder joint by the capillary action of molten solder in contact with stranded or braided copper wire.

Vacuum Extraction

Vacuum extraction is illustrated in Figure A-2. Solder is removed from a solder connection by applying a vacuum to molten solder through a heated hollow tip. The rework device also contains a collection chamber which collects and solidifies the waste solder and clipped leads.

When there is a need to remove a soldered-in component from a printed wiring assembly the easiest method available usually is the solder wick. Other than the normally available flux and soldering iron, the only material required is braided stranded copper wire. For two and three leaded components the solder wick method usually yields good results; however, for multileaded components and thick PWBs the vacuum extraction method has been found superior. Unfortunately, the vacuum extraction technique is somewhat cumbersome to implement. In addition to requiring special extraction equipment, a tip size and vacuum magnitude must be selected to match the rework situation. For critical rework situations, such as removal of a 14 lead DIP, the superior results obtained with vacuum extraction usually make the additional effort worthwhile.

\section{APPLICATION}

When properly applied, the solder wick and vacuum extraction rework methods can successfully and reliably remove components from printed wiring assemblies; however, if improperly applied, they can result in extensive damage to the printed wiring board: The following information and guidelines are suggested in the use of these rework techniques. 


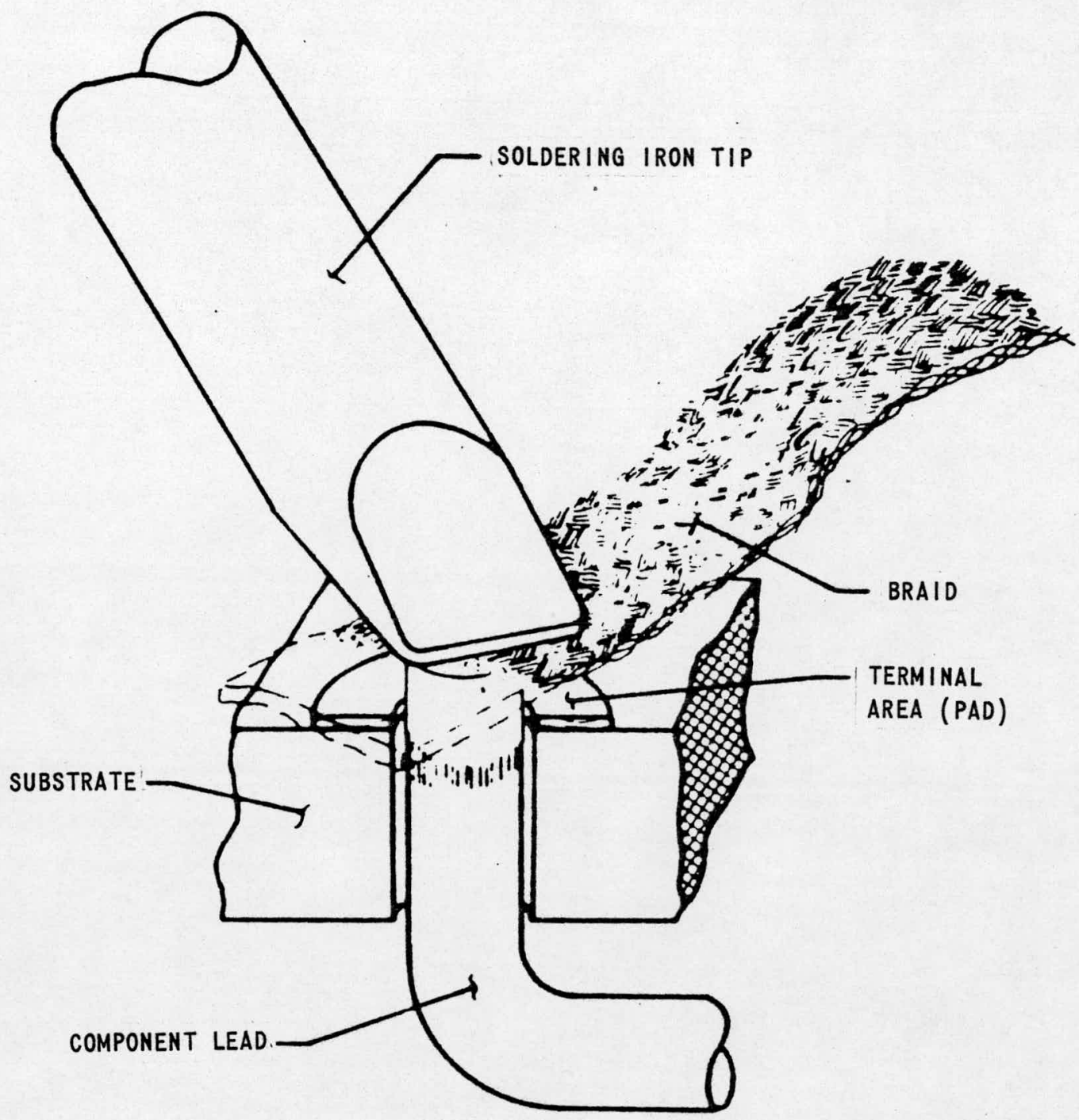

Figure A-1. Solder Wick Technique (Institute of Printed Circuits Drawing)

\section{Solder Wick}

- Solder wick quite often results in a residual sweat joint that cannot be easily removed with wick. It is possible to break the sweat joint by touching the joint with a hot iron and simultaneously moving the component lead.

- Because of sweat joints, solder wick is best suited to (and limited to) two or three leaded components or multileaded components where leads can be individually removed. 


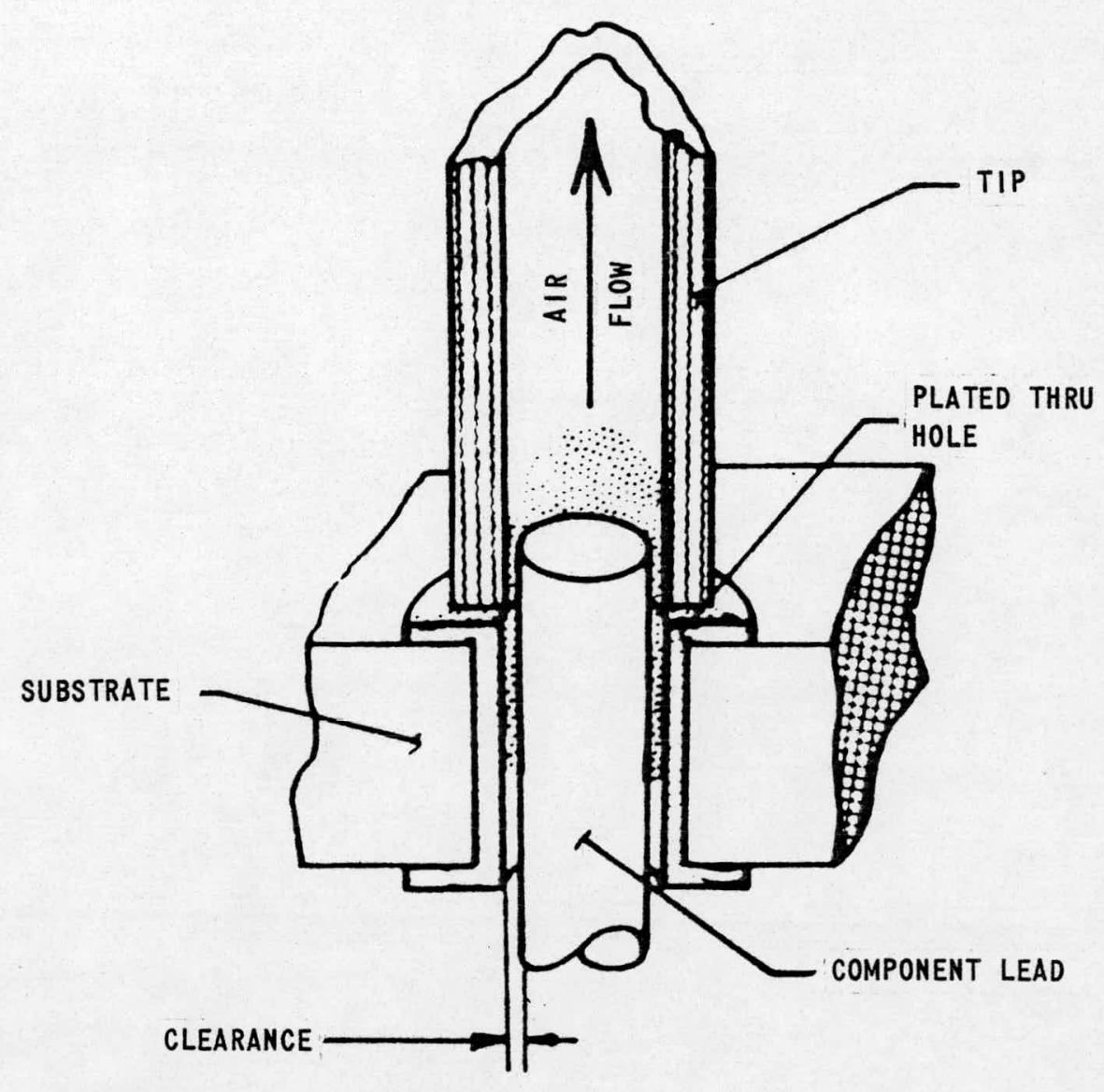

Figure A-2. Vacuum Extraction Technique (Institute of Printed Circuits Drawing)

- Generous use of flux is suggested with solder wick. The flux enhances the capillary action of the braided copper wire and seems to protect the PWB base material surrounding the solder connection being reworked.

- Solder wick is the best known method for reworking lap joints.

- It is best to apply solder wick at a point where maximum surface contact is made with the connection (Figure A-3).

- To avoid burning the board, the heating element should be positioned above conductive paths and lands rather than PWB base material.

\section{Vacuum Extraction}

- Extraction tip size must be matched to the rework situation. Figure A-4 illustrates the proper tip-joint combination. 


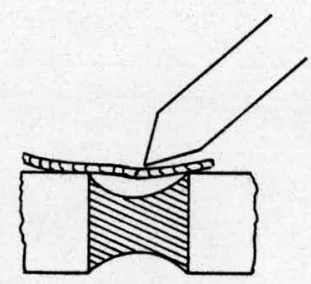

INCORRECT (CONCAVE CAUSED

BY REMOVING COMPONENT BEFORE APPLYING SOLDER WICK)

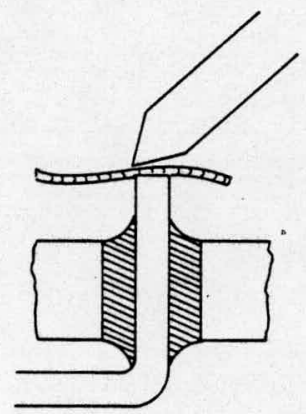

INCÖRRECT

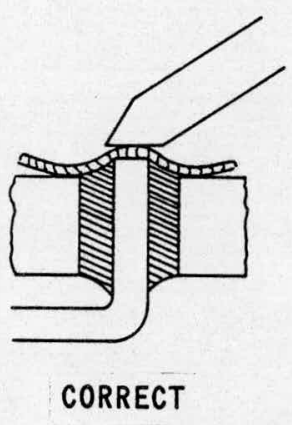

Figure A-3. Proper Application of Solder Wick

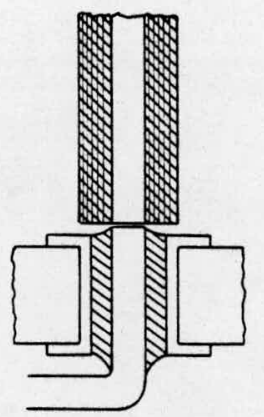

TIP TOO SMALL

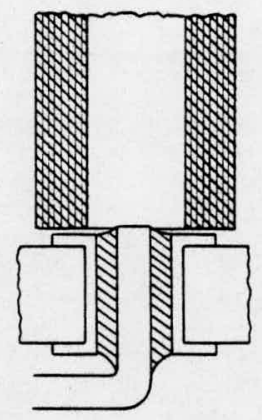

TIP TOO LARGE; MAY DAMAGE PWB

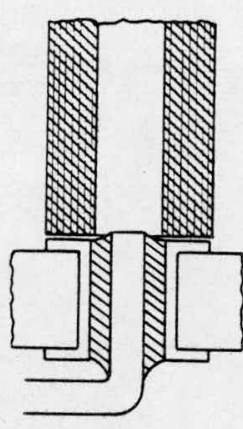

PROPER TIP JOINT COMBINATION

Figure A-4. Proper Vacuum Extraction Tip-Joint Combination

- If there is no available extraction tip which closely matches the joint to be reworked, it is sometimes possible to obtain satisfactory results by tilting the extraction tip as illustrated in Figure $\mathrm{A}-5$.

- The use of flux with the solder extraction method is not necessarily required. The outgassing of heated flux tends to limit visibility during the solder extraction process. 


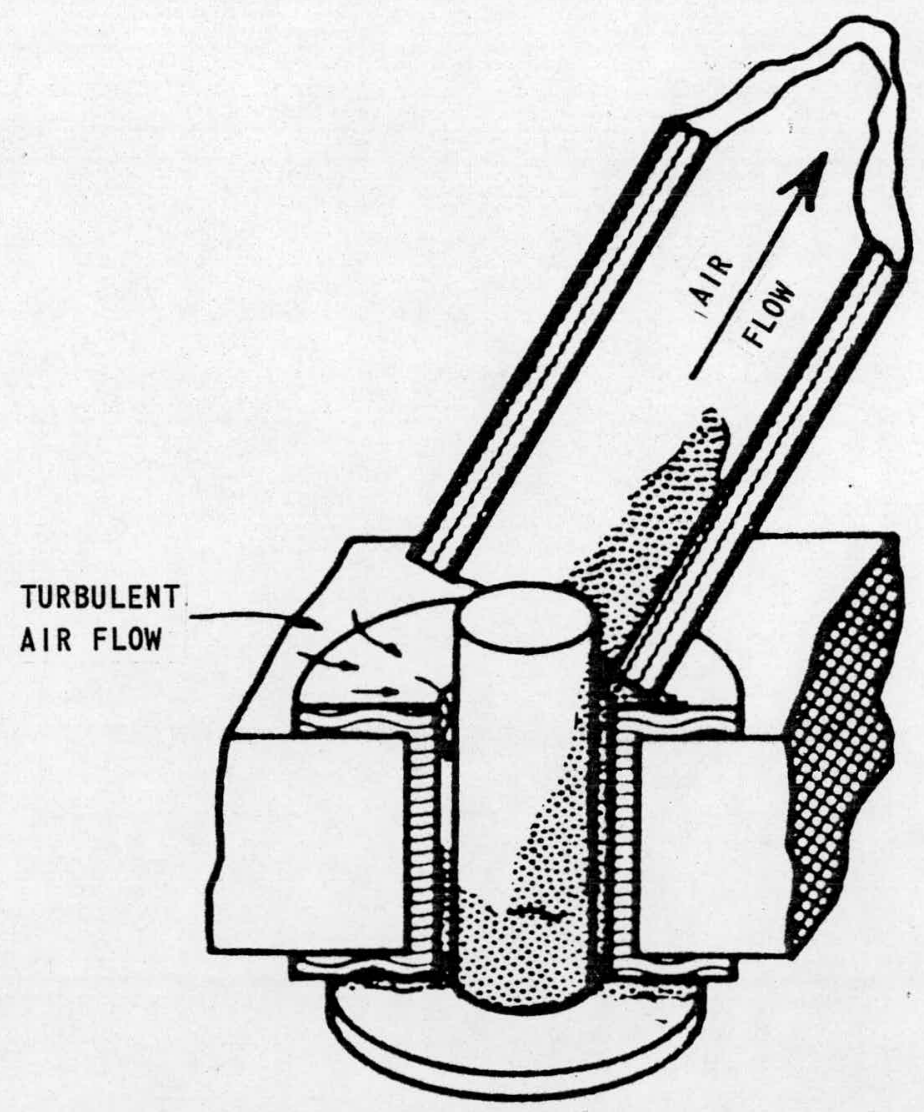

Figure A-5. Extraction Tip

Positioning (Institute

of Printed Circuits

Drawing )

- Sweat joints can generally be eliminated by agitating the component lead with the extraction tip during solder removal (Figure $A-6$ ).

- Because of its ability to eliminate sweat joints, vacuum extraction is the best known method for removing multileaded components (more than three leads).

- There are a number of different suppliers and models of vacuum extraction equipment. The equipment generally differs in tip size, tip configuration, vacuum mode, solder collection system, and so forth. Equipment should be chosen to match the rework situation. 


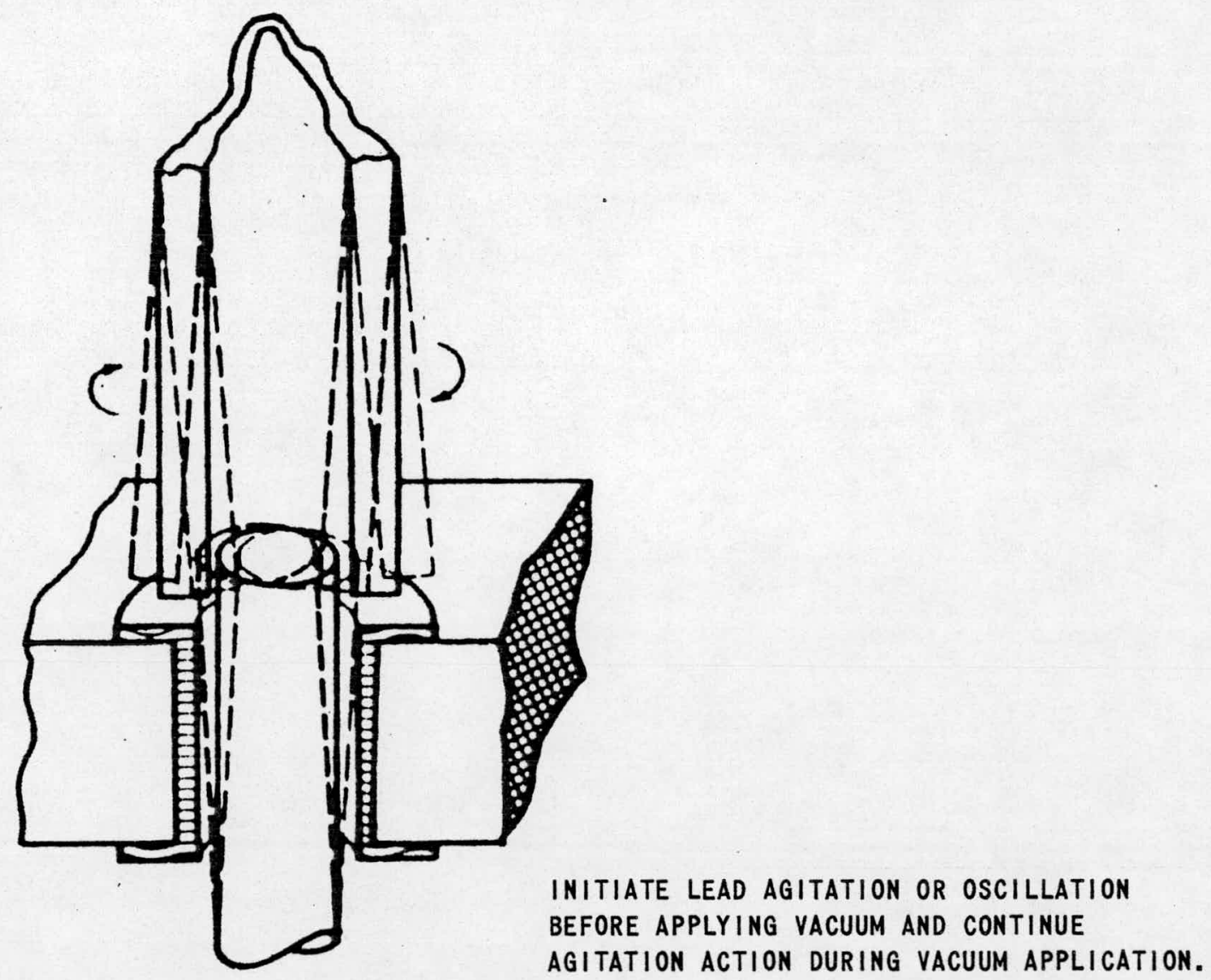

Figure A-6. Elimination of

Sweat Joints by

Agitating Component

Leads (Institute

of Printed Circuits

Drawing )

\section{TEMPERATURE CONSIDERATIONS}

Evaluations indicate that the vacuum extraction rework technique can yield a lower and more repeatable rework temperature profile than the solder wick technique. The internal temperature of ten identical PTHs was monitored during rework. Figure A-7 shows the temperature profiles of the holes reworked by vacuum extraction and Figure A-8 shows the temperature profiles of the holes reworked by solder wick. The operating temperature of the rework tools was the same for both methods. Soon after the PTH reaches the melting temperature of solder with the vacuum extraction technique, the solder can be extracted and the heat source removed. For the capillary action to be completed with the solder wick technique, 


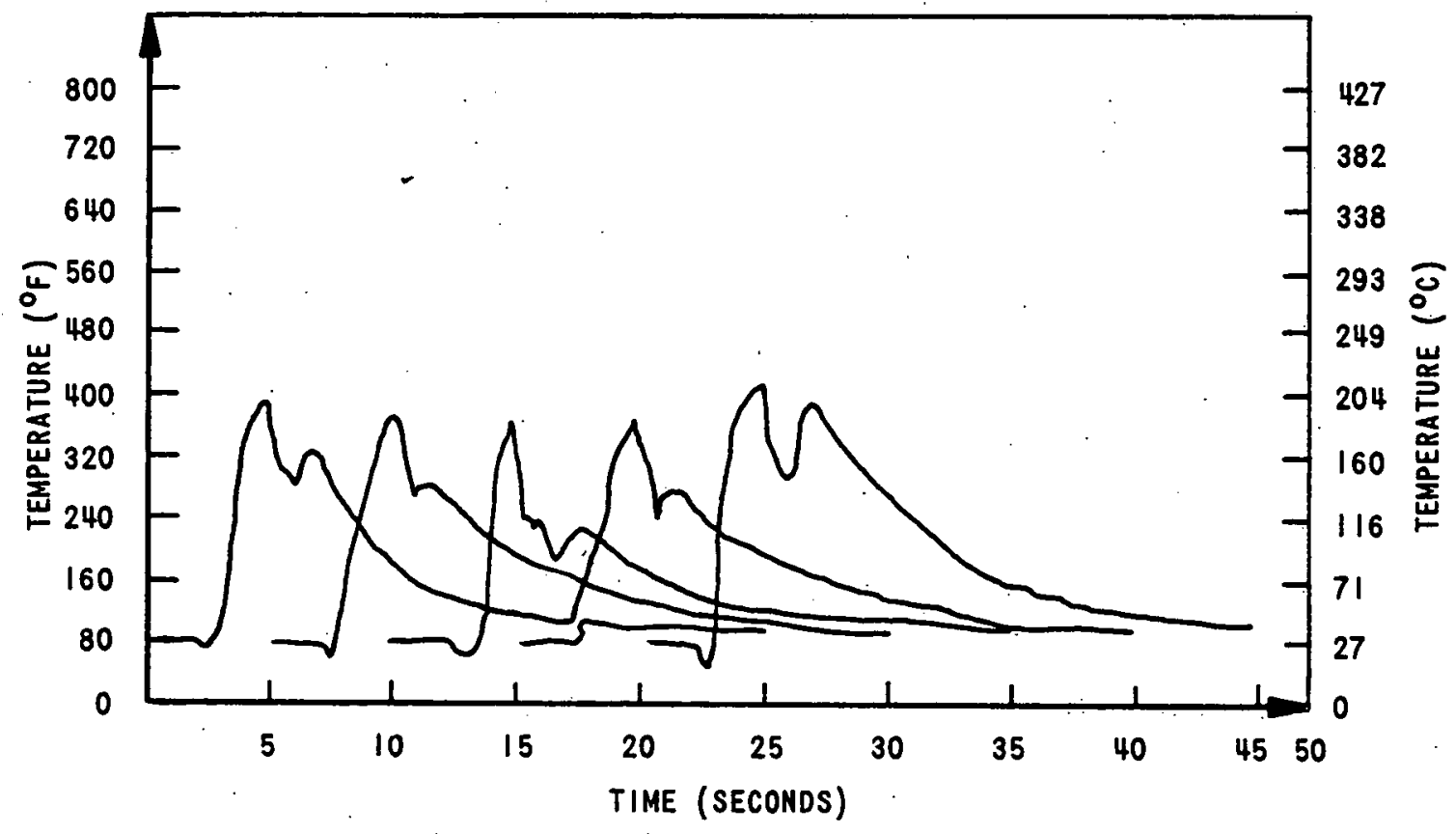

Figure A-7. Temperature Profiles of PTHs Reworked by Vacuum Extraction

the heat source must remain in contact with the joint for some time after reaching the melting temperature of solder. In addition, visibility of the completion of the capillary action is usualiy obscured by the braided copper wire. As a result, the solder connection reaches a higher temperature and is exposed to high temperature for a longer period of time with the solder wick rework technique.

Application of the vacuum during the vacuum extraction process causes the temperature of the extraction tip to be lowered. This is important to consider since the operator may or may not want tip temperature to go below the melting temperature of solder. The temperature profile of the extraction tip depends on the starting temperature of the tip, the length of time the vacuum is applied, the magnitude of the vacuum, and the equipment being used. Figure A-9 presents representative temperature profiles for the Pace Model Sx300 Sodr-X-Traction System. 


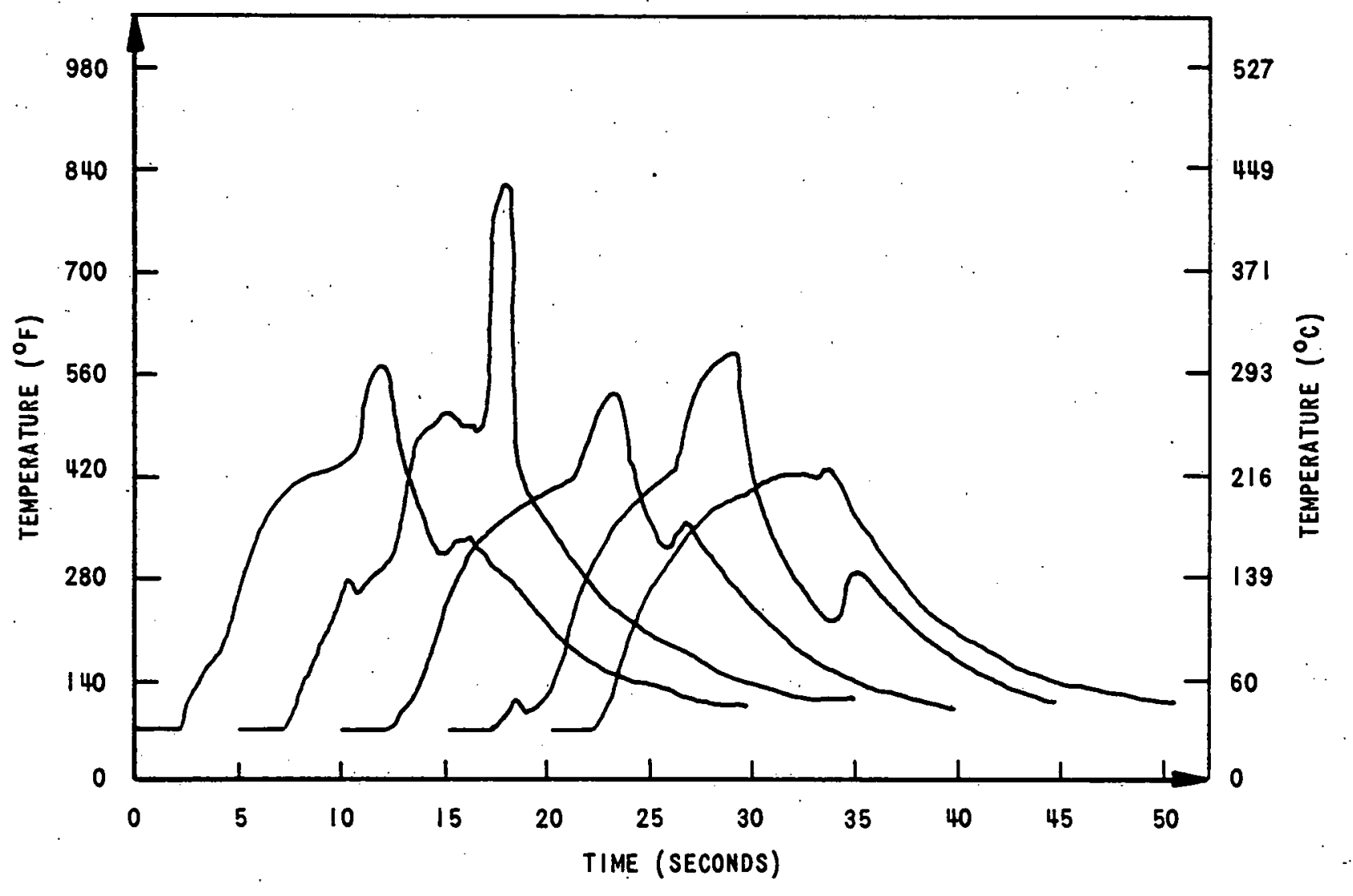

Figure A-8. Temperature Profiles of PTHs Reworked by Solder Wick 


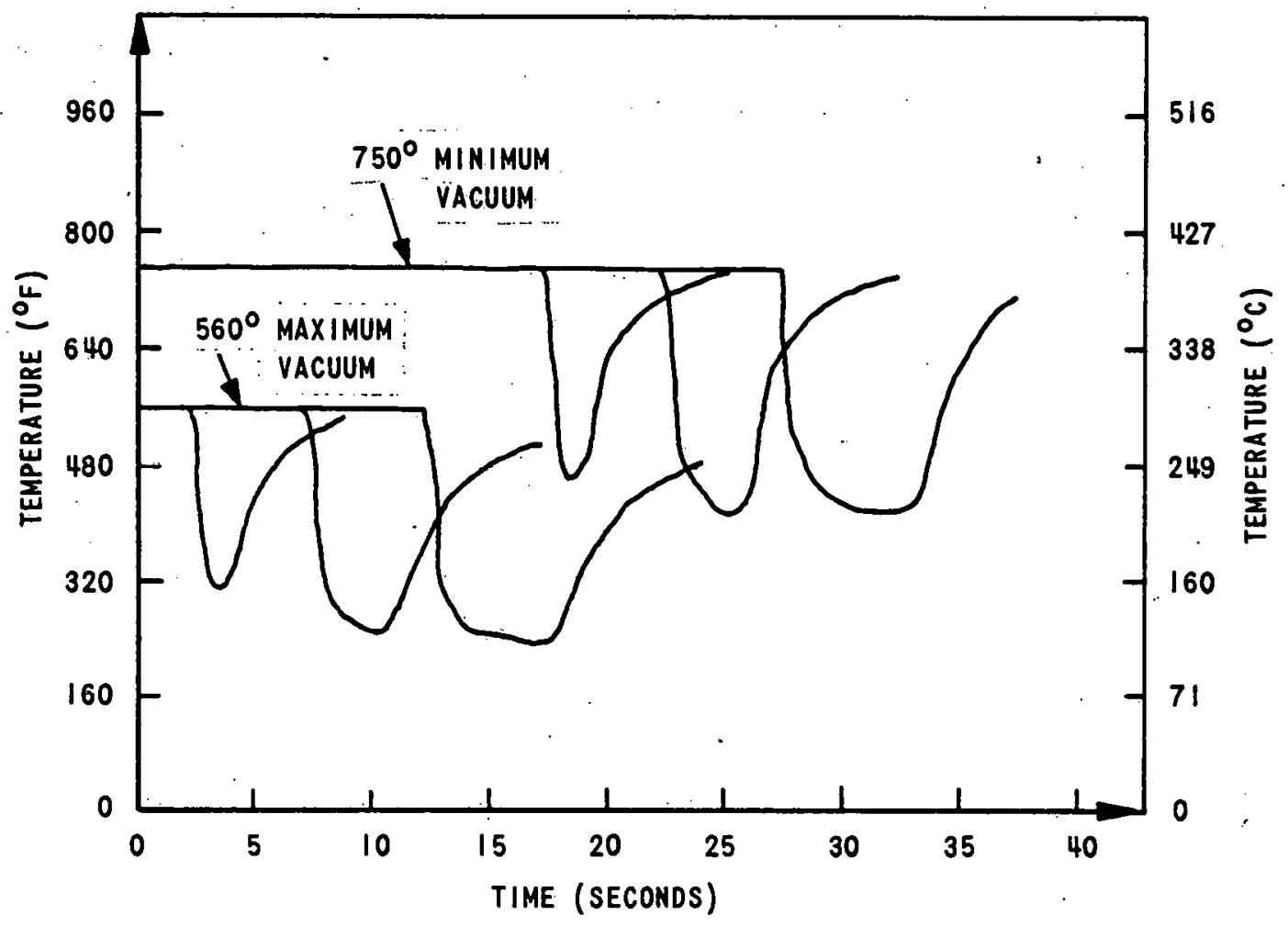

Figure A-9. Representative. Temperature Profiles for the Pace Model $5 \times 300$ Sodr-X-Traction System 
Copy

R. Bulcock, ERDA-KCAO

1

J. J. Baremore, SLA

A. D. Andrade, SLL

D. N. Tanner, SLL

J. D. Corey, D/554

L. Stratton, D/554

R. P." Frohmberg, D/800

D. H. Hax, D/800

J. A. Morrison, D/800

F. A. Spies, D/800

W. H. Deterding, D/814

J. L. Wilson, D/821

T. A. Wiley, D/842

D. W. Clements, D/845

R. K. Johnson, D/845

R. L. Morgan, D/845

R. S. Morris, D/845

R. C. Douglass, D/845

J. H. Lynch, D/845

W. R. Sprague, D/845

V. E. Alley, D/862

R. E. Kessler, D/864 